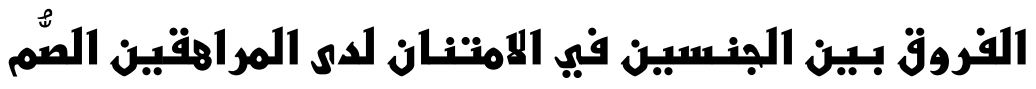

محمد عبد العظيم خلف الله (*)

ملفص:

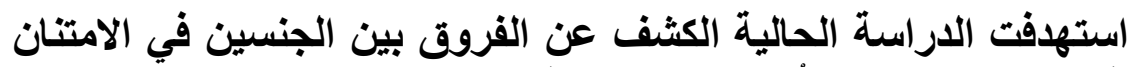

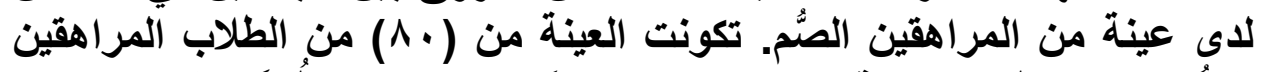

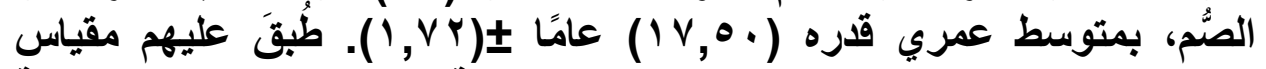

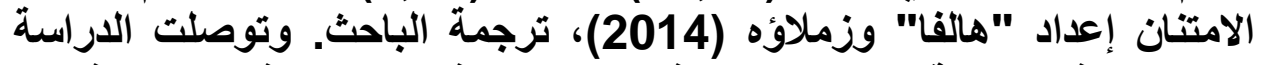

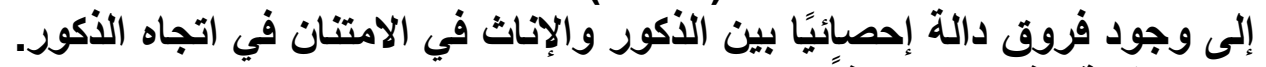

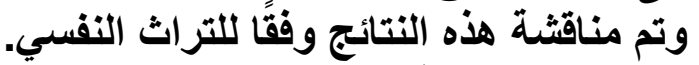

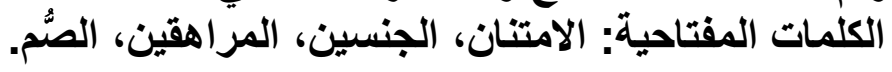

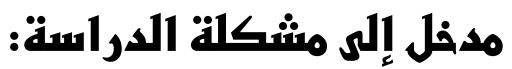

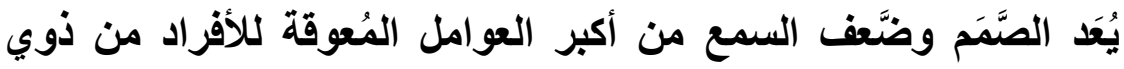

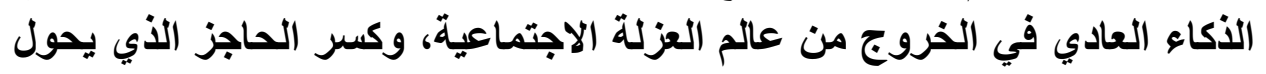

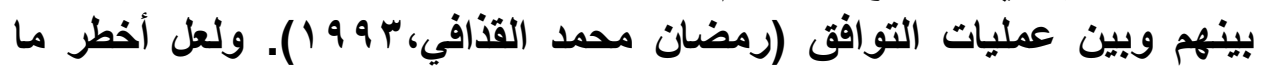

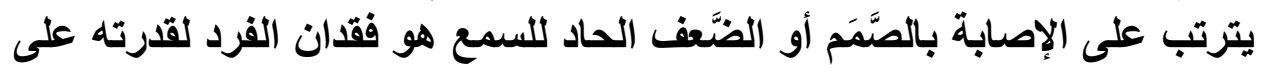

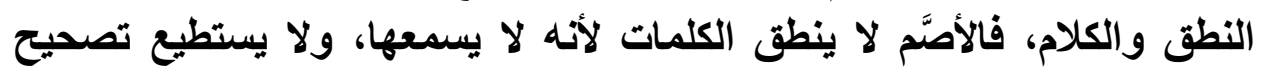

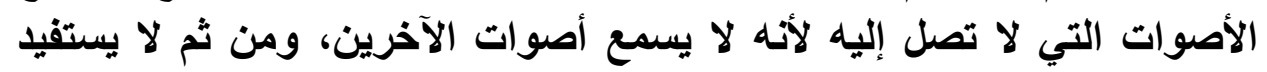

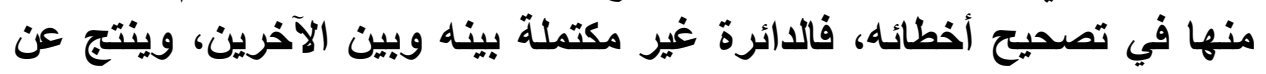

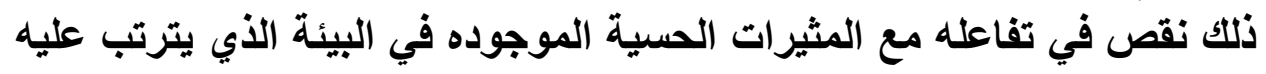

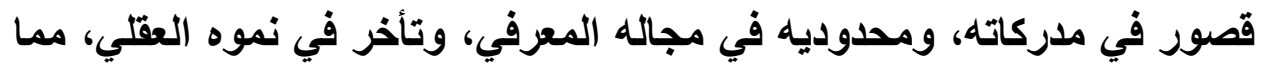

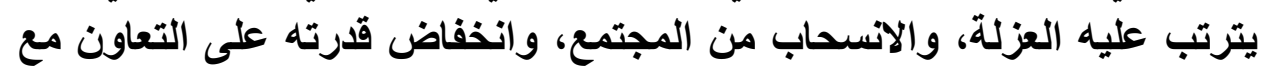

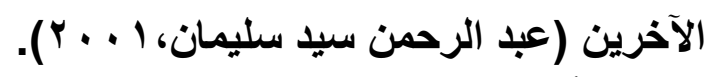

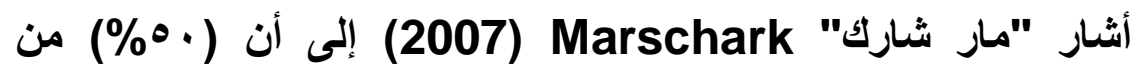

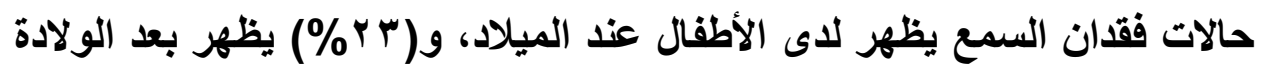

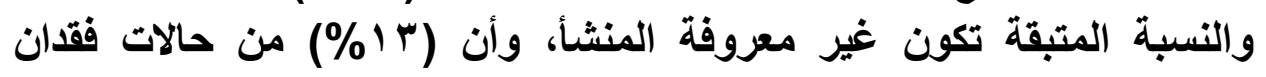

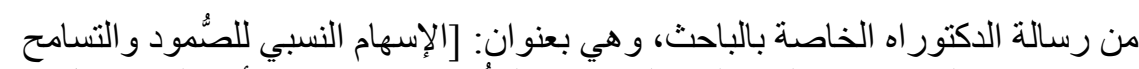

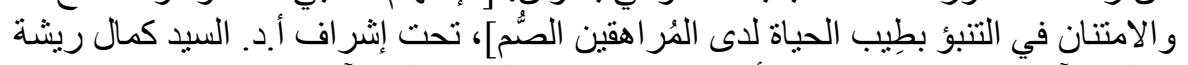

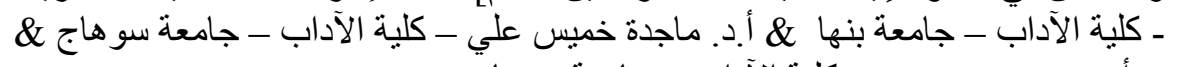

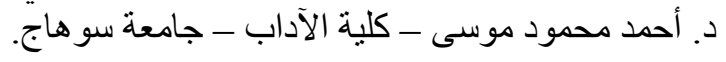




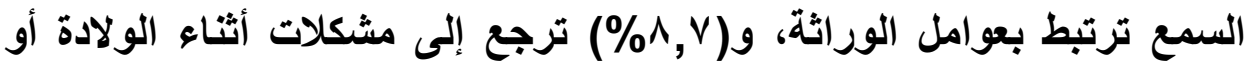

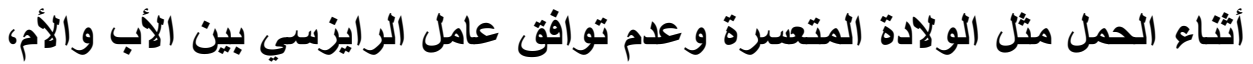

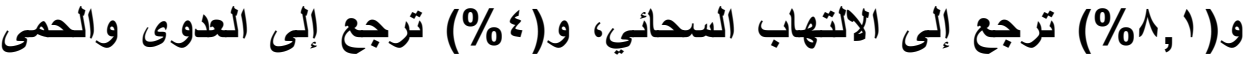

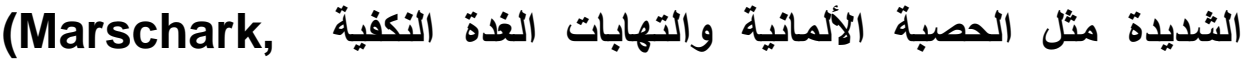

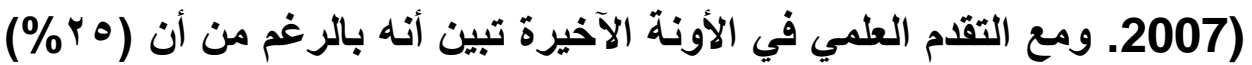

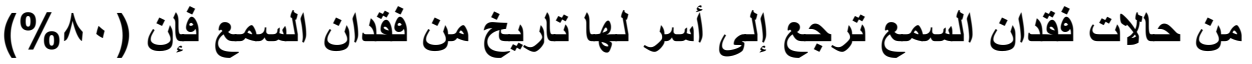

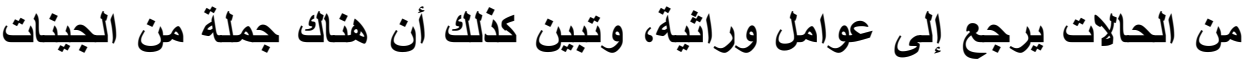

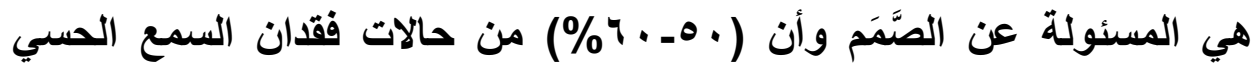

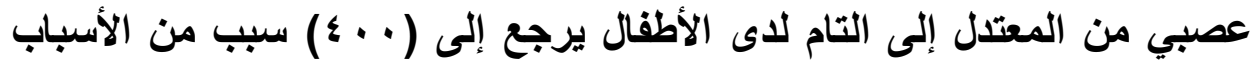

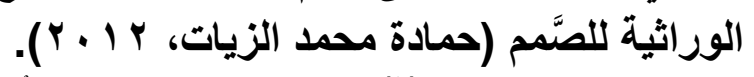

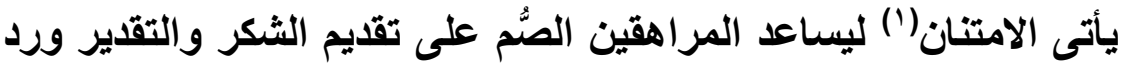

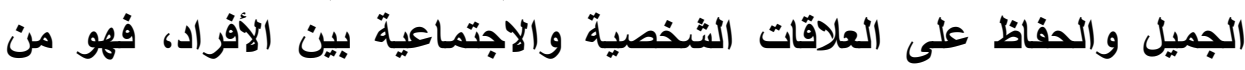

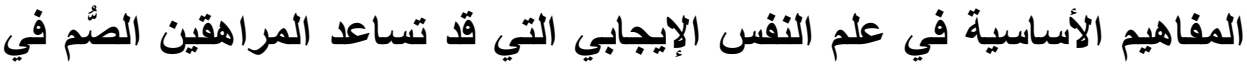

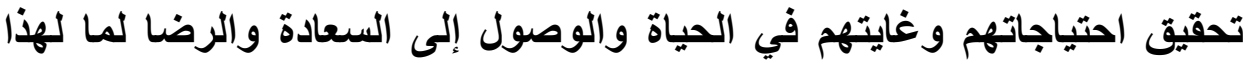

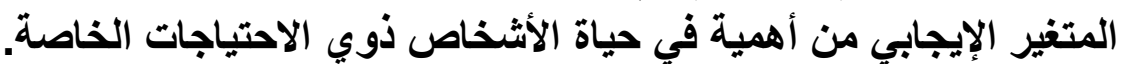

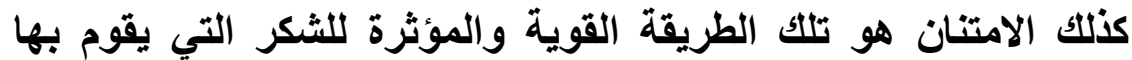

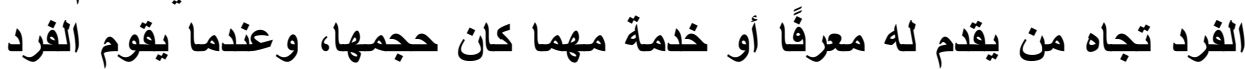

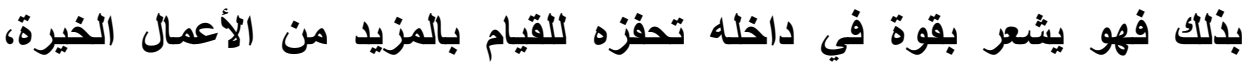

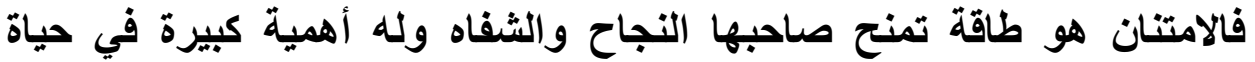

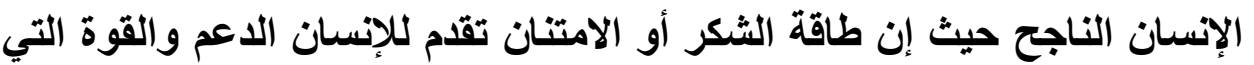

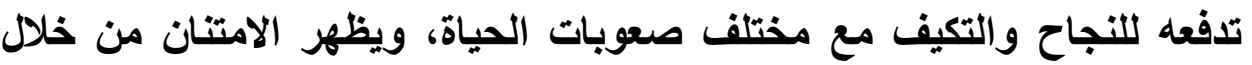
حسن السلوك والتهذيب والثعور الحقيقي بالتقير للآخرين (حواء إبراهيم

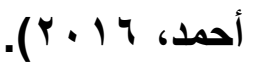

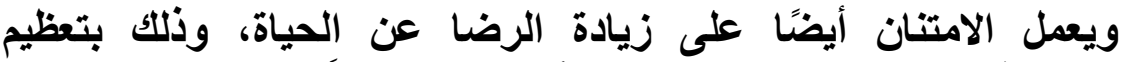

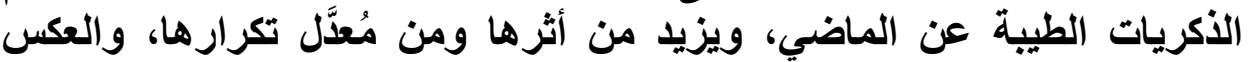

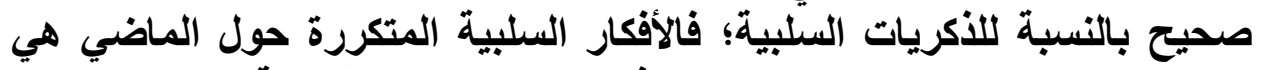

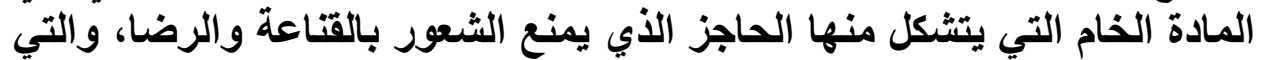

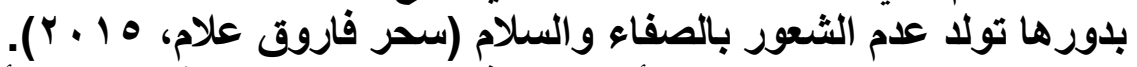

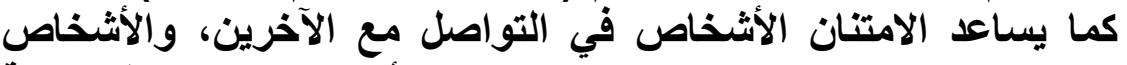
مرتفعي الامتنان يمتلكون القدرة على منح السعادة؛ لأن الامتنان يرتبط بالآنالة الآلة

1) Gratitude. 
الانفعالية والمشاعر الإيجابية بما في ذللك الرضا، والسعادة، والفخر، والأمل (Emmons \& McCullough, 2003)

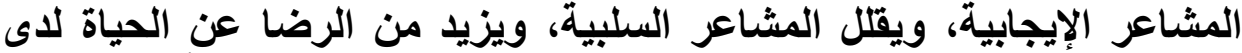

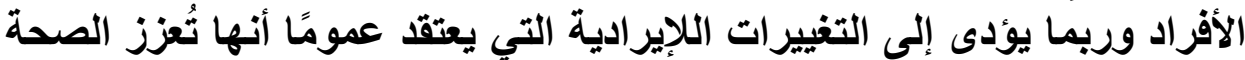

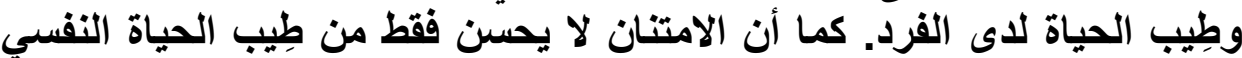

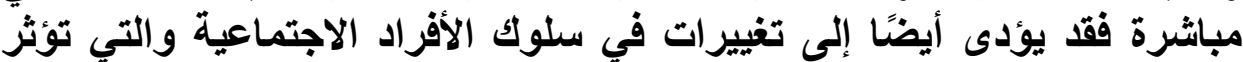
بدورها في طِيب الحياة (Polak \& McCullough, 2006). وجد الباحث أن هناك تباين في نتائج الاراسات السابقة التي تتطلق

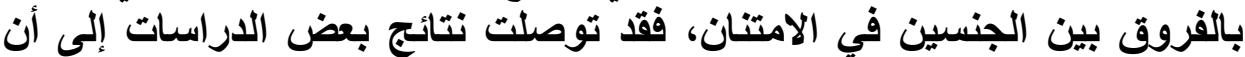

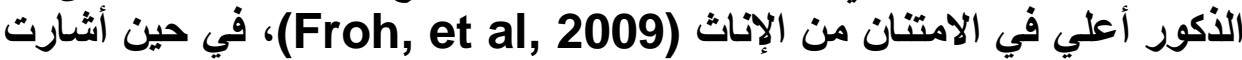

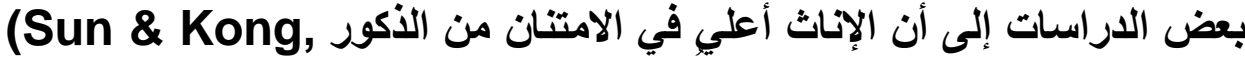

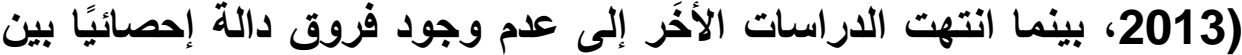
الذكور والإناث في الامتنان (Sood \& Gupta, 2012).

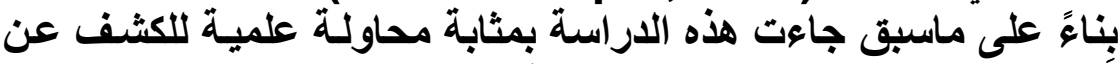

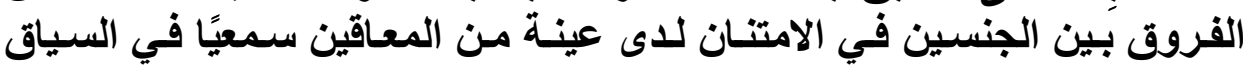

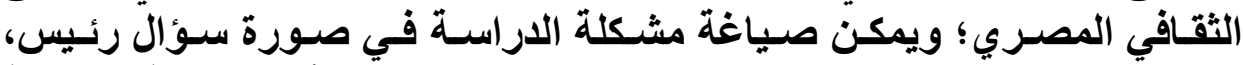
مفاده: هل توجد فروق في الامتنـان بين الذكور والإتـاث أفراد عينة الدراسـة

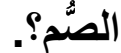

أهمية الدراسةة: يمكن الإشارة إلى أهمية الدراسة الحالية وفقًا لمبررات نظرية، وأُخَرَ تطبيقية، وذلك على النحو الثَّلي:

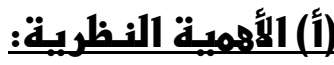

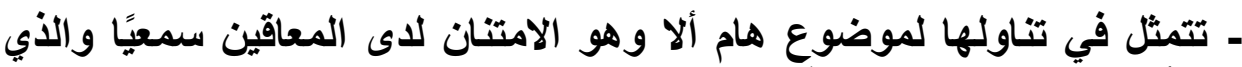

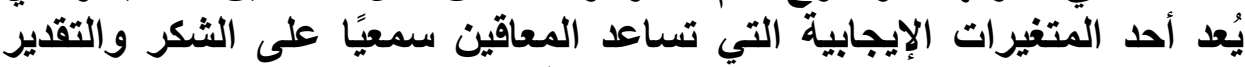
ورد الجميل والحفاظ على العلاقات الاجتماعية.

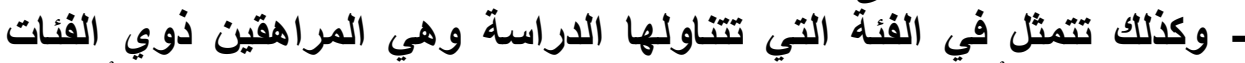

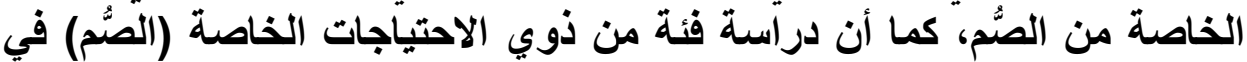

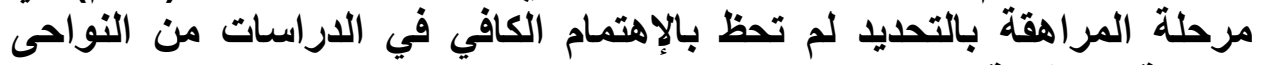
النفسية والوقائية.

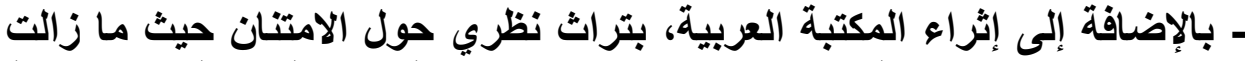
الداسات محدودة للغاية على متفير الامتنان في البيئة العربية عامة، والأنية والمصرية

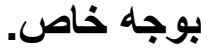




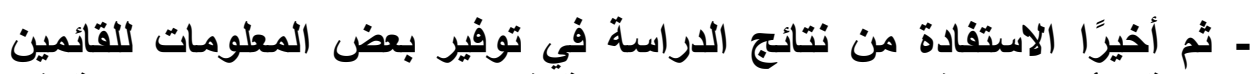

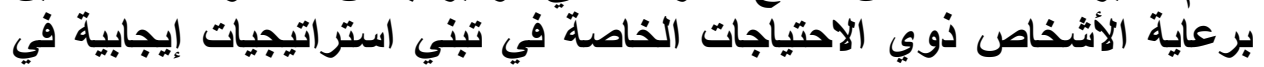
التعامل مع الآخرين في حياتهم اليومية.

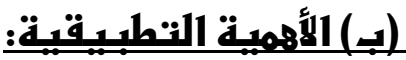

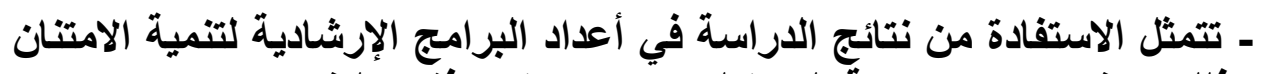

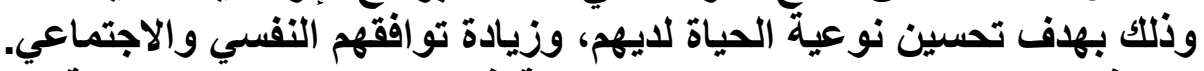

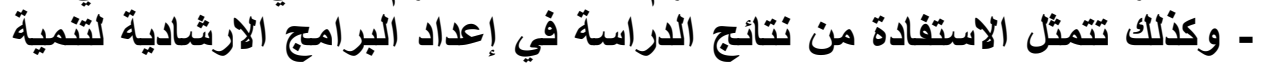

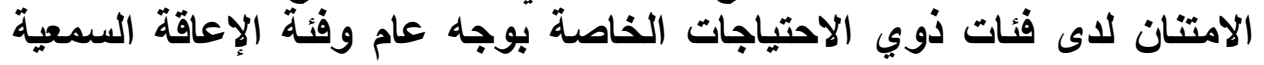

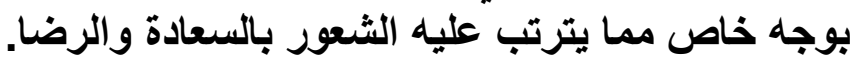

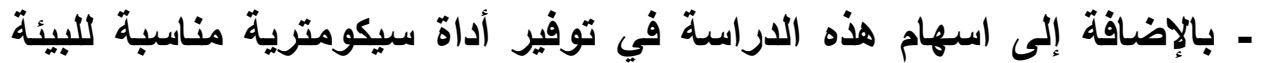
العربية في قياس الامتنان لاى أحدى فئات ذوي الاحتياجات الخاصة (المعاقين

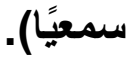

هدف الدراسةة : استهرفت الدراسة الحالية الكثف عن الفروق في الامتنان بين الذكور والإناث أفراد عينة الدراسة الصُّم.

مغاهيم الدراسة : تناولت الاراسة المفاهيم والمصطلحات الثَّلية:

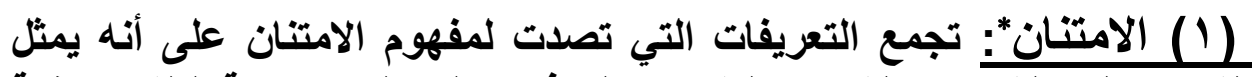

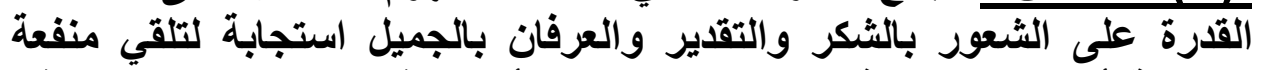

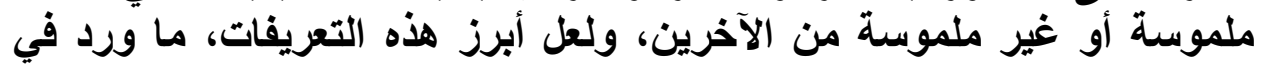

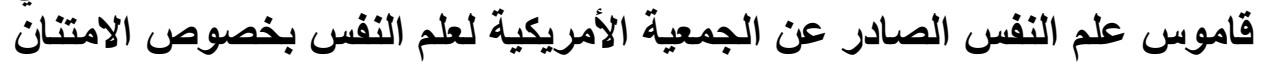

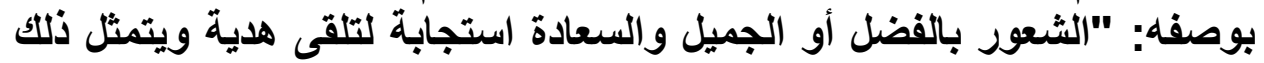

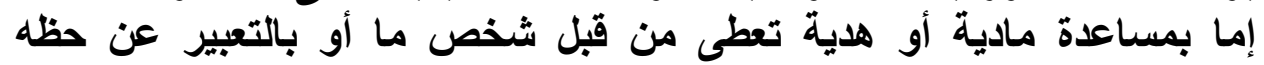

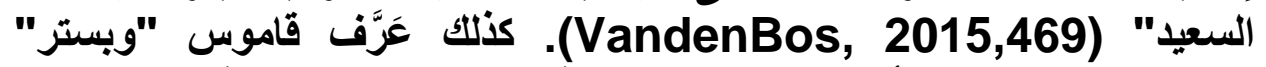

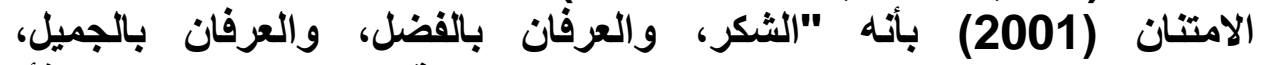

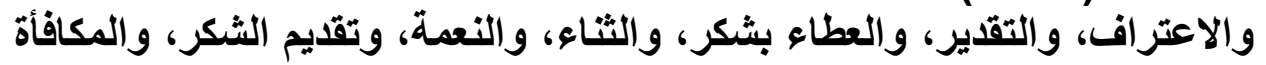
أو الجزاء (Morehead, 2001,355) تناول عدد من الباحثين الامتنان بوصفه "(نفعال بثعر به الفرد تجاه

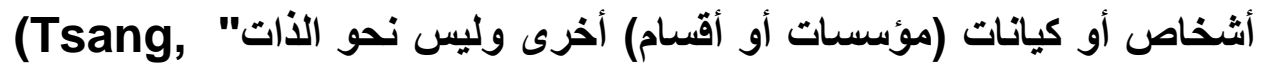

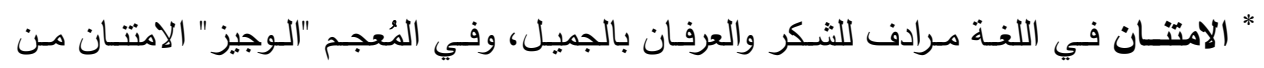

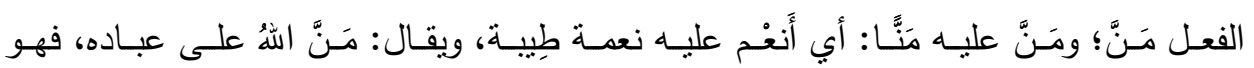

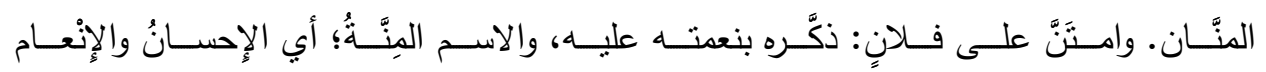

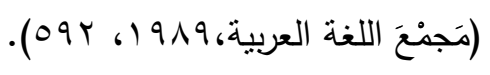




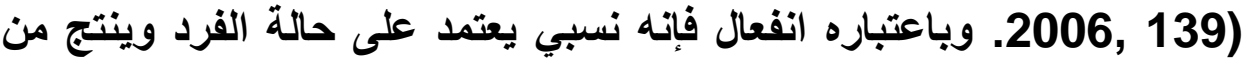

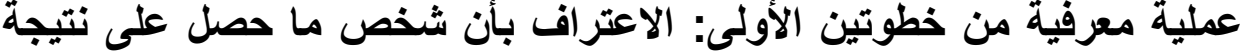

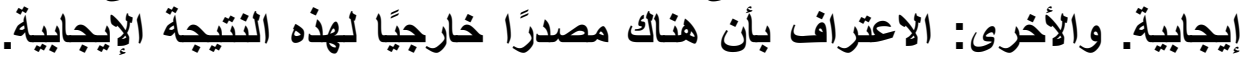

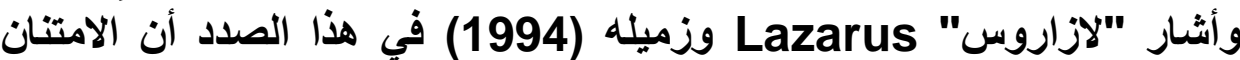

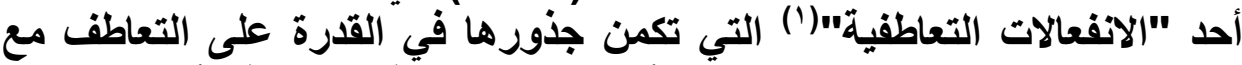
الآخرين، فجوهر الامتنان الاعتراف أو التقدير للعطية الإيثارية؛ أي الاعتئ الاعتراف

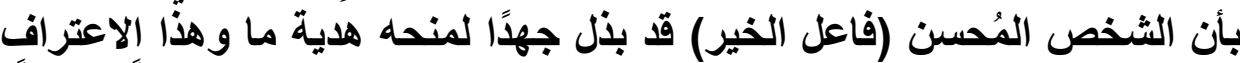

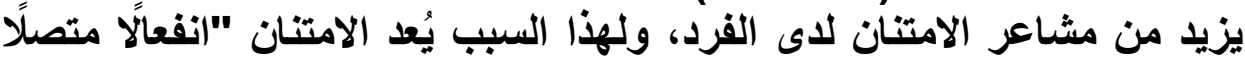

(Emmons \& McCullough, 2003,377 ; بالتعاطف من .Froh,Yurkewicz, \& Kashdan, 2009,2) في حين أشار "إيمونز" (2004) إلى أن الامتنان يمثل "شعورًا

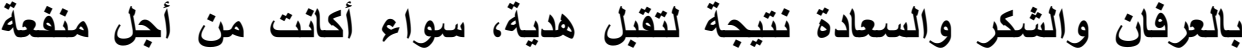

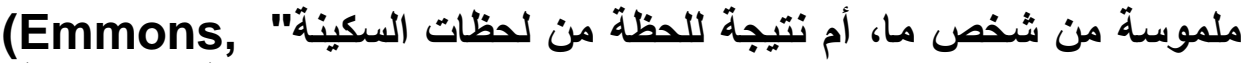
2004B,4)

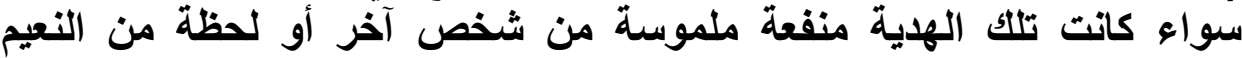

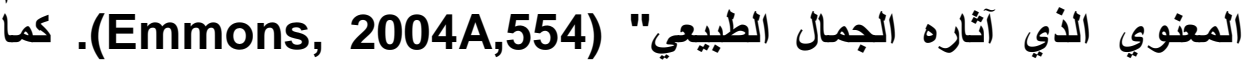

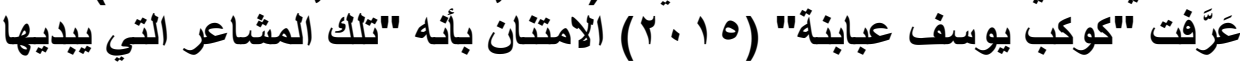

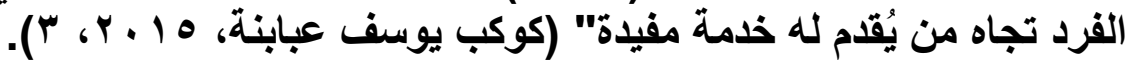
ومن خلال ما سبق عرضه يمكن للباحث أن يقدم التعريف الإجرائي

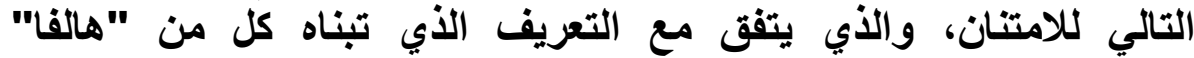
Hlava

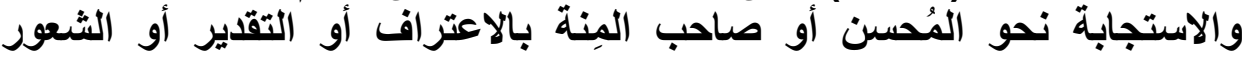
بالفضل أو تقديم الشكر له نظير ما قدمه من منفعة أو فائدة للشخص مهما كاتت

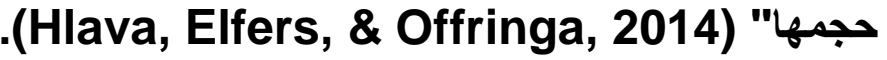

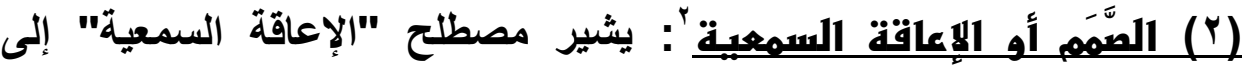

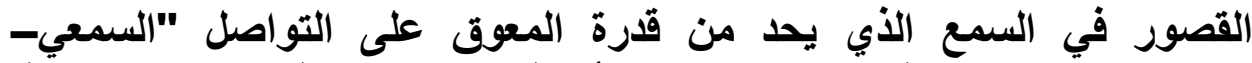

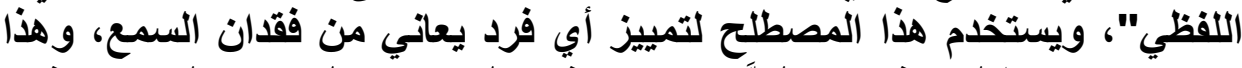

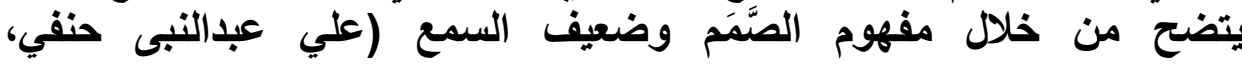
. $(\mathrm{V}, \mathrm{Y} \cdot \mathrm{s}$

ورد الصَّمَم في معجم علم النفس والطب النفسي بأنه "الغياب الكلي أو أوابر

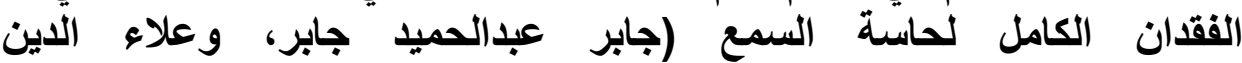

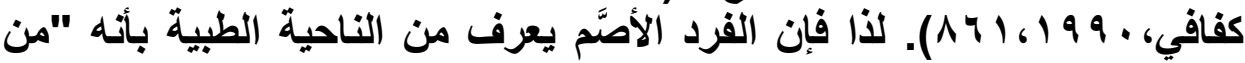

1) Empathic Emotion.

1) Hearing impairment. 


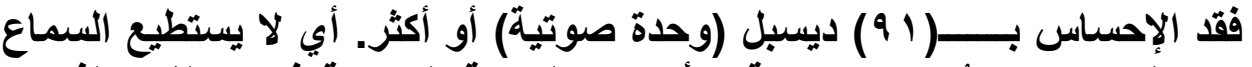

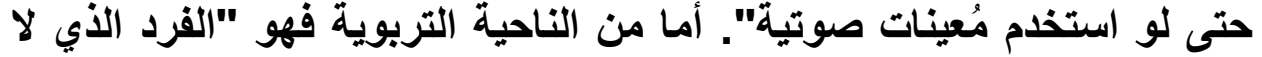

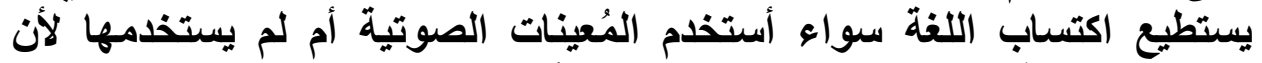

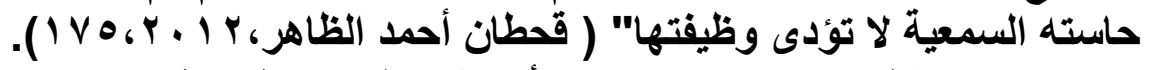

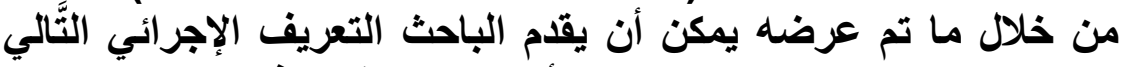

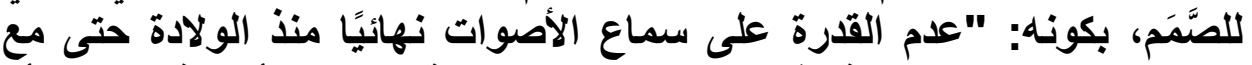

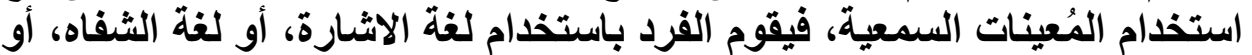
غيرها من الوسائل التي تساعده فلى التى التواصل مع الآخرين". الإطار النظري للدراسة: ] [1] [كونات الامتنـاز: أثنار "ماكولو" وزملاؤه (2002) إلى أن العناصر الإيجابية والسلبية، والئية

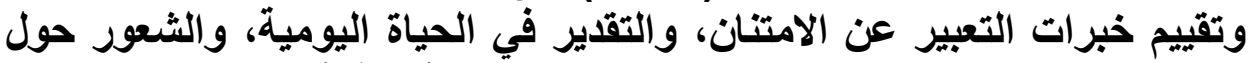

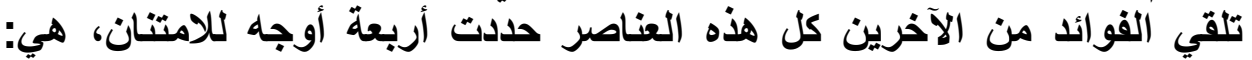

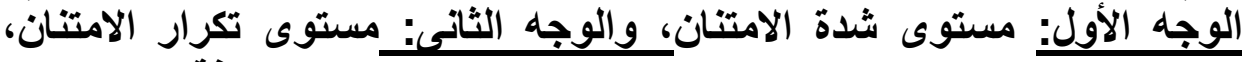
والوجه الأثلث: الأنئ (McCullough, Emmons, \& Tsang,2002) الامتنان كعامل واحد استنادًا إلى التكرار، والثدة، والكثافة للشعور بالامتنان (Wood, Froh, \& Geraghty, 2010) أما "واتكينز" Watkins وزملاؤه (2003) فحدادوا ثلاثة أبعاد

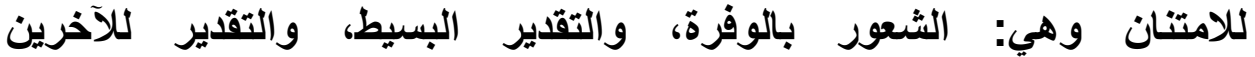
(Watkins, Woodward, Stone, \& Kolts, 2003). وفي وفي السياق نفسه ينطوي الامتنان على ثلاثة أبعاد وهي: تقدير الناس، وتقدير الحياة،

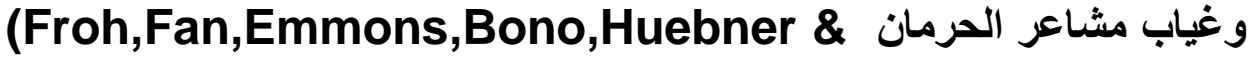
Watkins, 2011 ; Wood, Maltby,Stewart, \& Joseph,

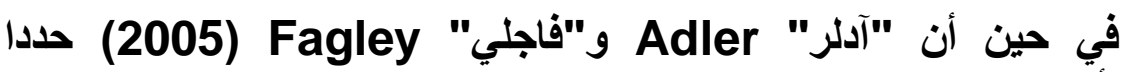
.2008)

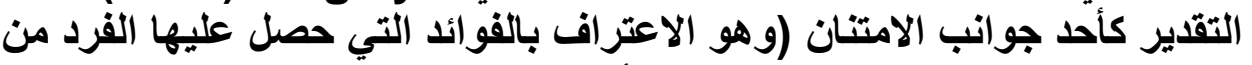

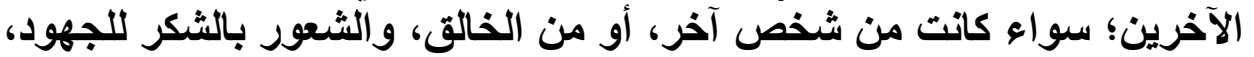

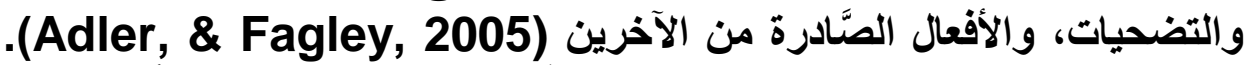
بينما حدد "فيتسجير الد" Fitzgerald ثلاثة مكونات الآنات للامتنان هي: (أ) إحساس

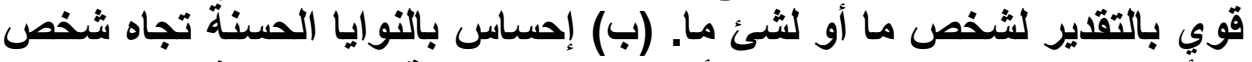

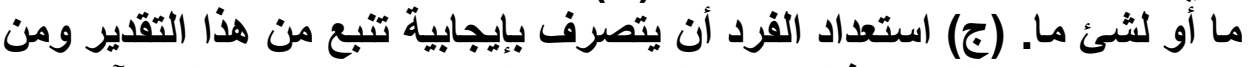

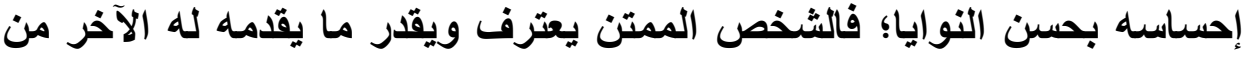


(Froh, Miller, \& Snyder,2007; Lambert, كرم وعطاء .Fincham, Stillman, \& Dean,2009)

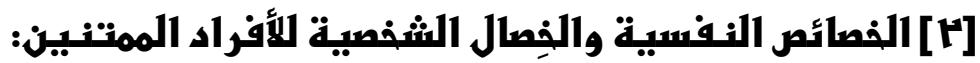

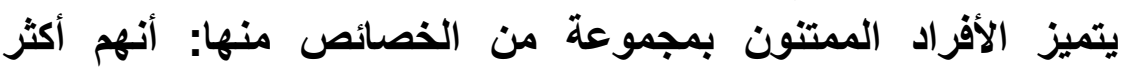

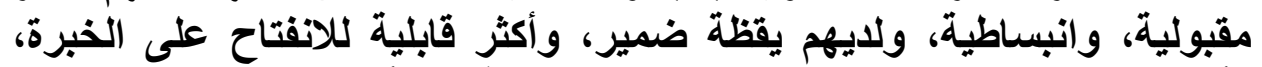

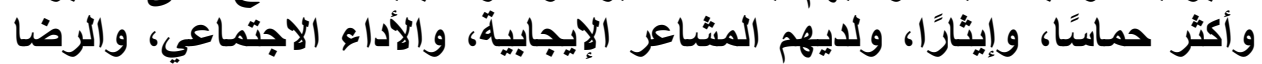

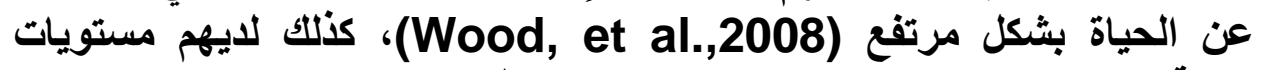
عالية من الوجدان الإيجابي، والتسامح، وطِيب الحياة، ولايهم مستويات

منذفة من الوجدان السلبي (Hill \& Allemand, 2011).

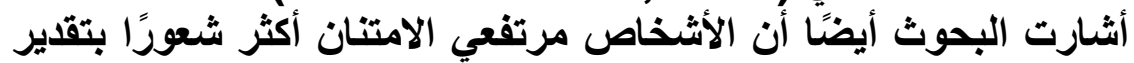

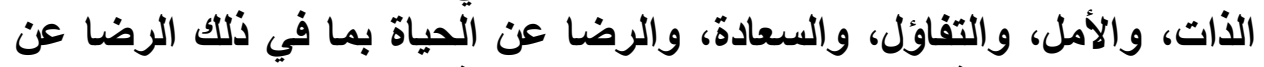

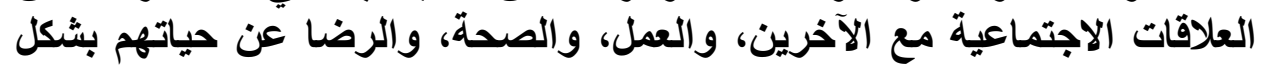
(Kong,Ding \& Zhao,2015; Robustelli \& عام الاخرين، وزملاوة (Whisman,2016) وفي السياق نفسه، أثشارت نتائج دراسة "ماكولو"

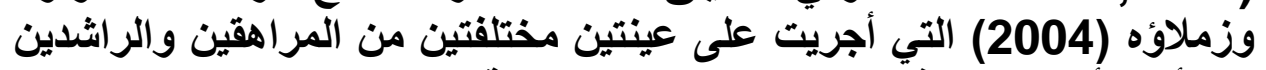

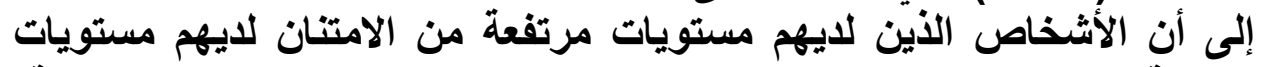

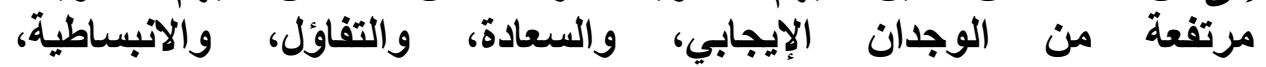
والاينية/الروحانية، والرضان عن ألحياة، ومستويات منخفضة من الوجدانيان

السلبي، والاكتئاب (McCullough,Tsang \& Emmons, 2004).

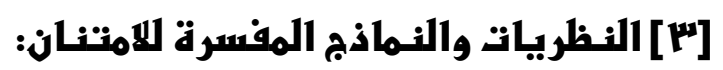

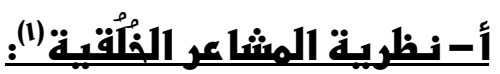

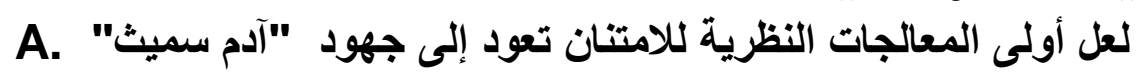

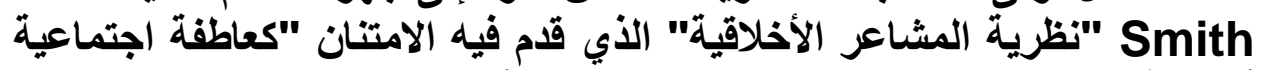

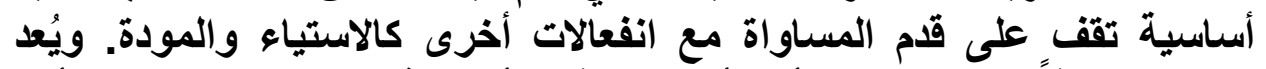

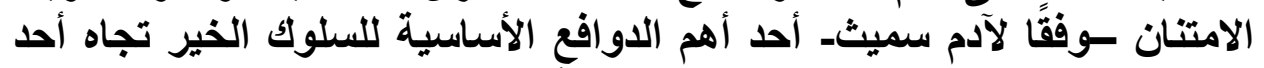

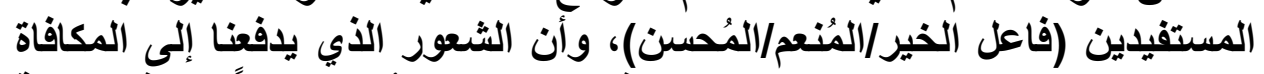

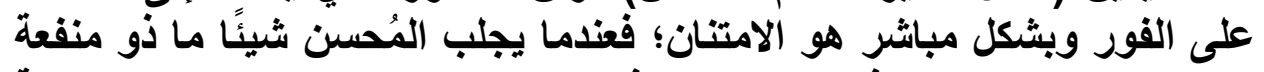

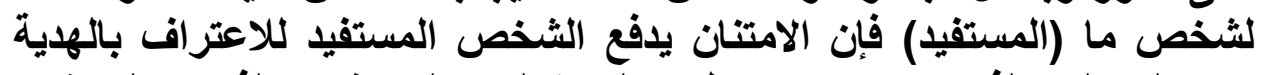

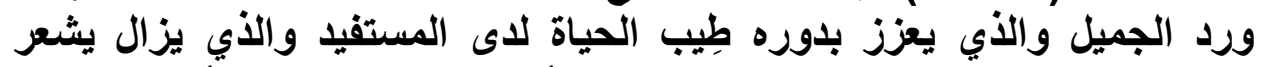

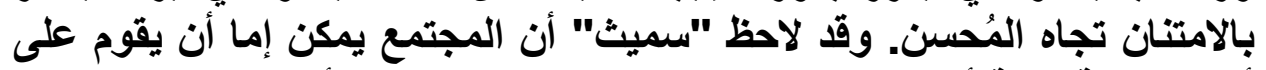

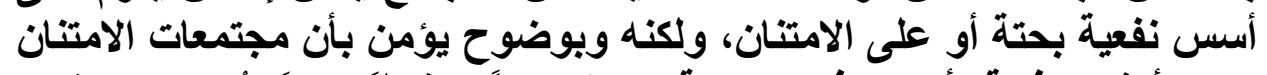

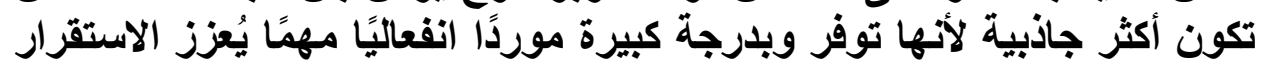

1) Moral Sentiments Theory. 


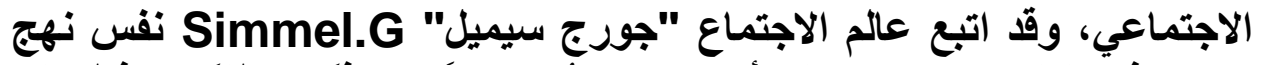

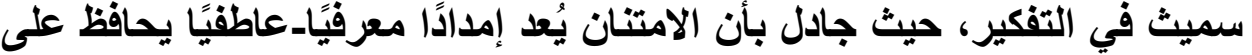

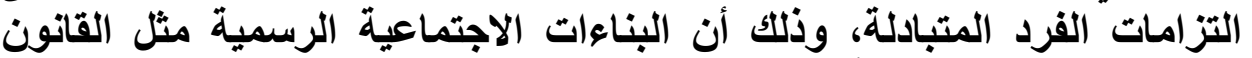

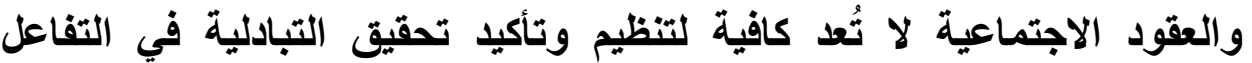

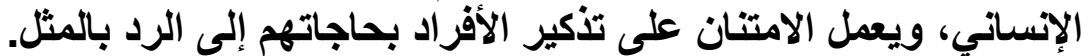

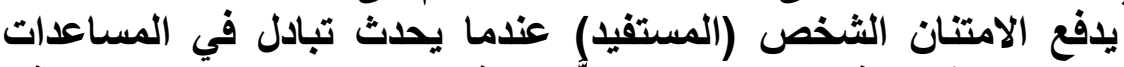

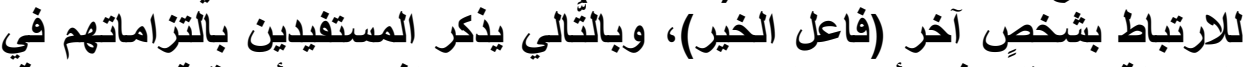

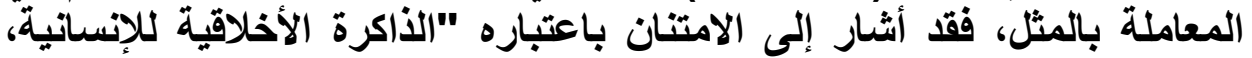

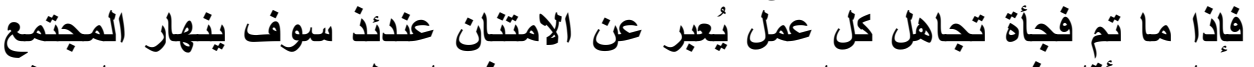

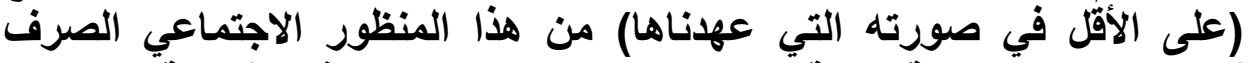

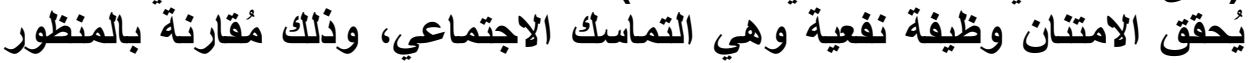

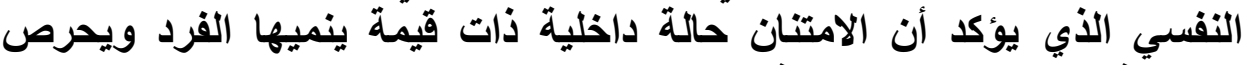

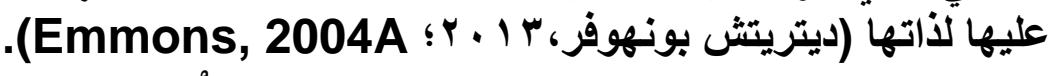

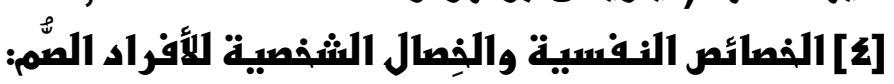

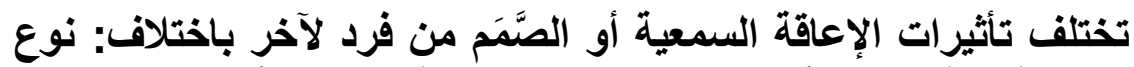

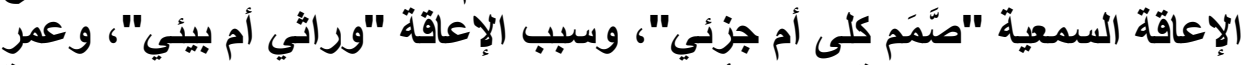

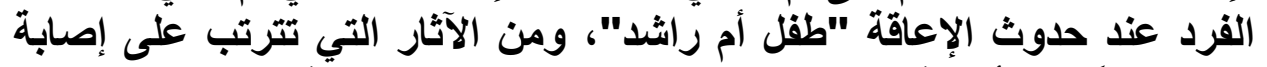

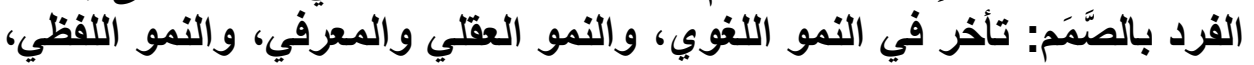

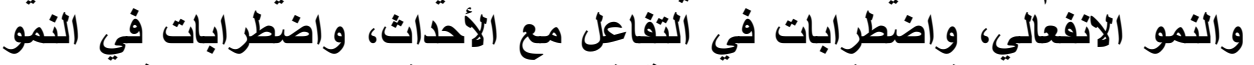

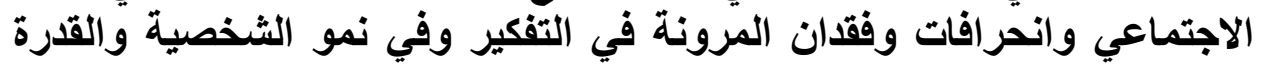

$$
\text { على التكيف (علاء الدين محمد خليل، ب ... ب). }
$$

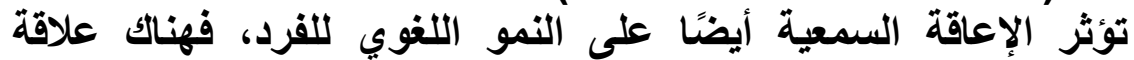

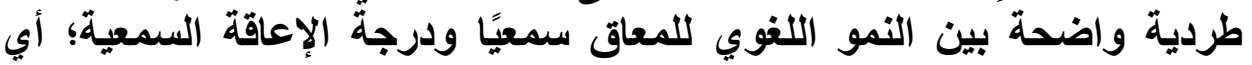

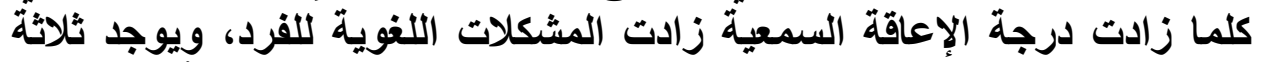

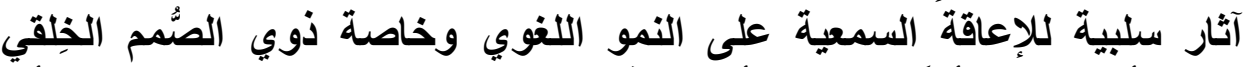

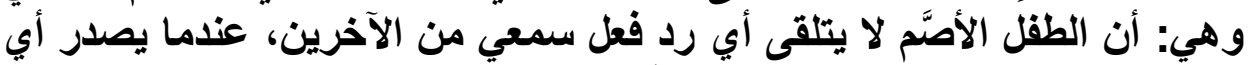

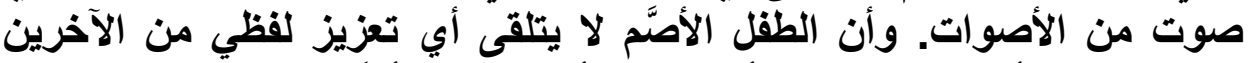

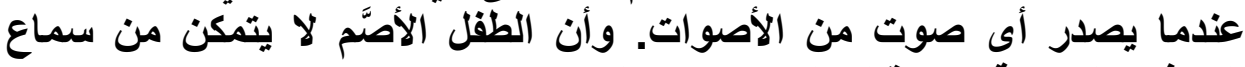

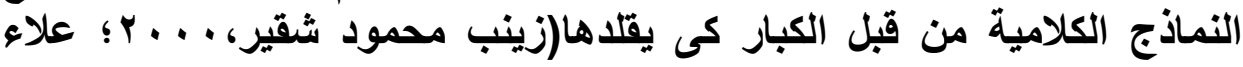

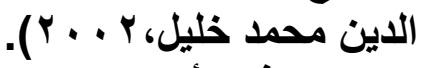

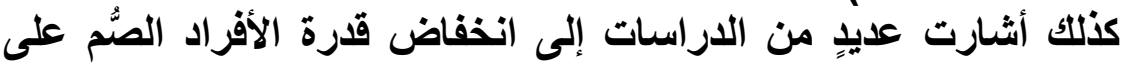

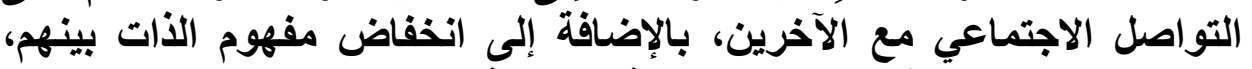

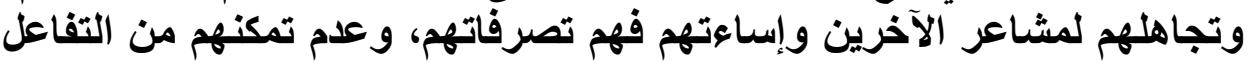

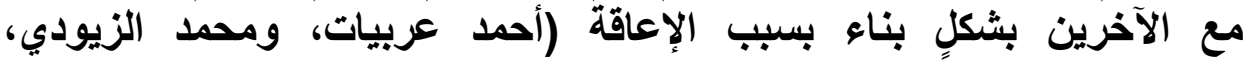




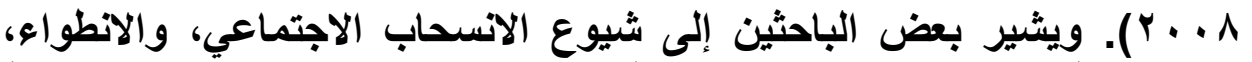

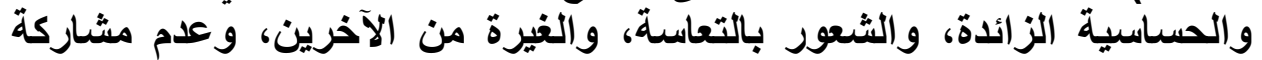

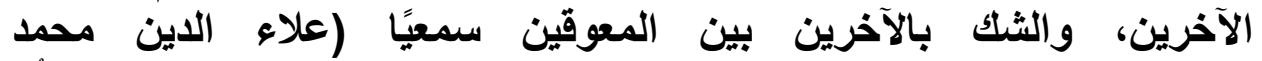

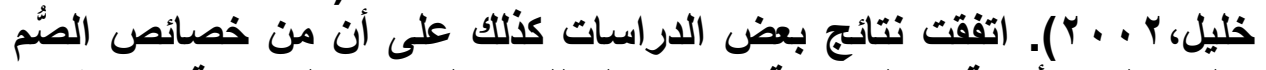

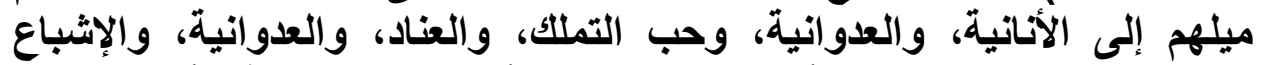

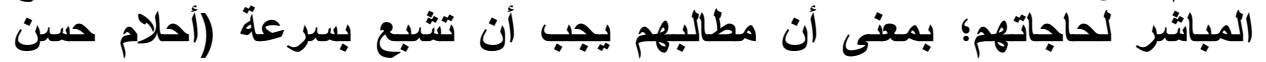

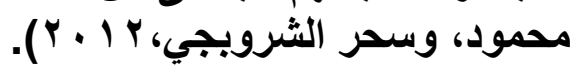

\section{الدراسات السابقةة:}

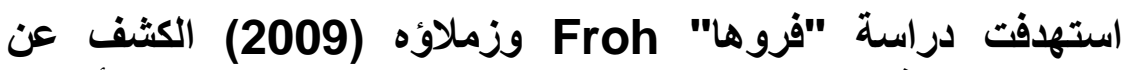

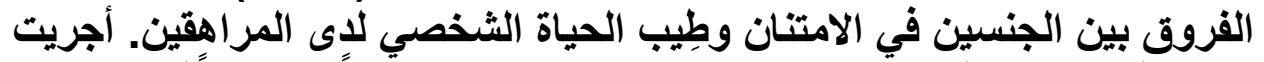

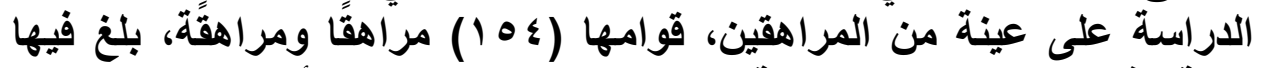

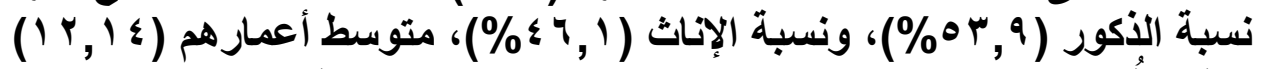

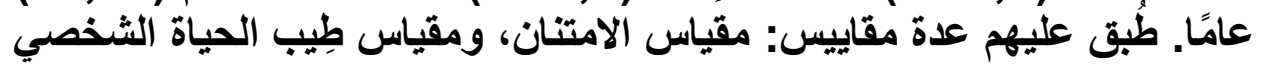

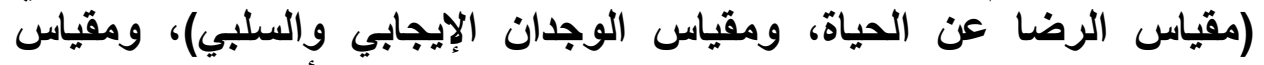

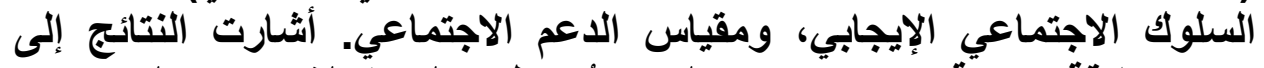

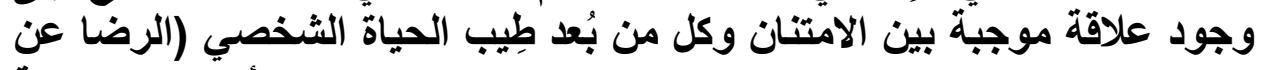

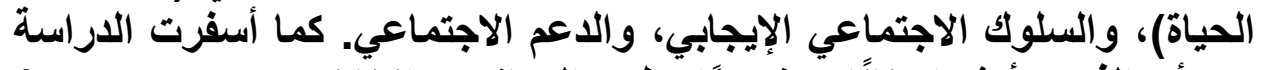

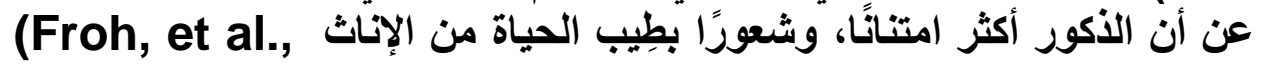

.2009)

كنلك استهدفت دراسة "الخوالدة" Al-Khawaldeh و"زيجاراك" اليومة Zegarac

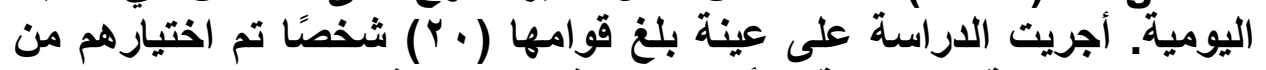

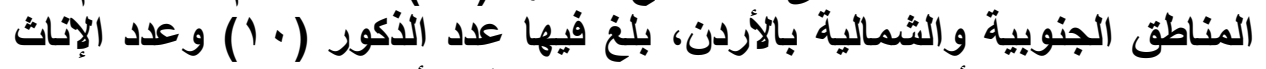

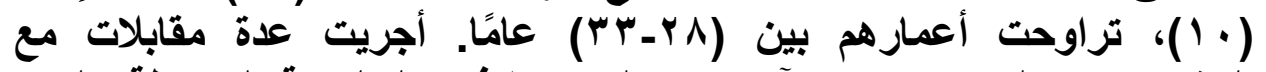

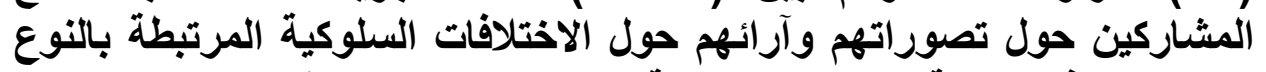

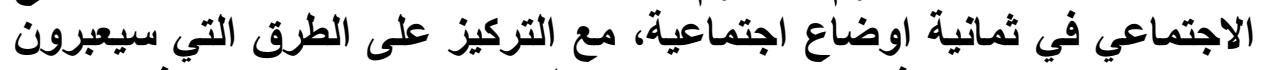

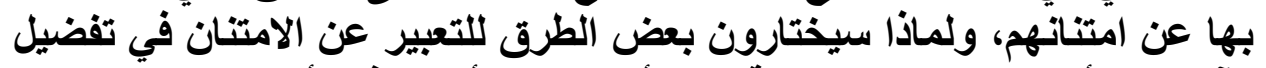

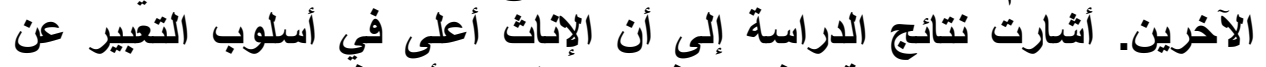

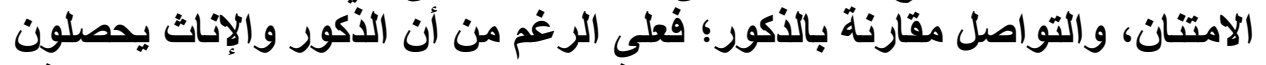

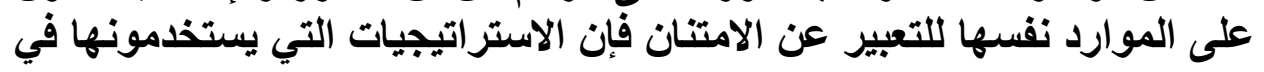

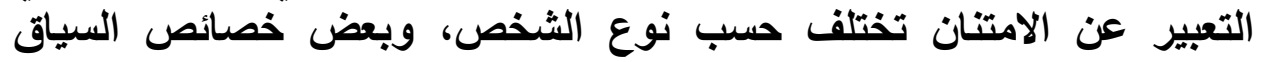
(Al-Khawaldeh, الاجتماعي على وجه الخصوص الوضع الاجتماعي للفرد .\& Zegarac, 2013) 


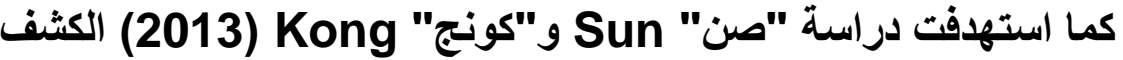

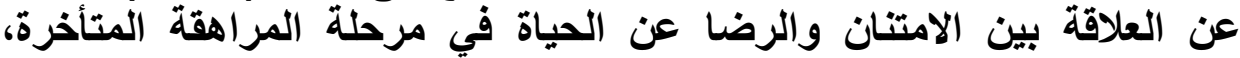

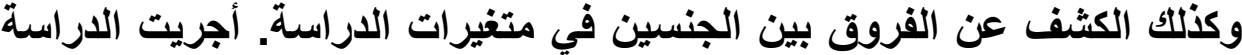

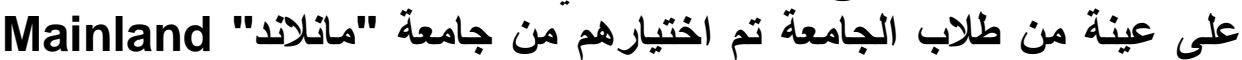

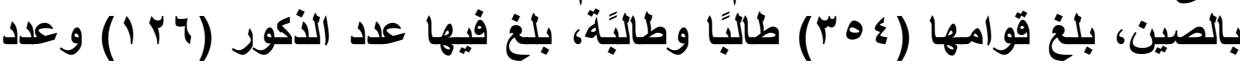

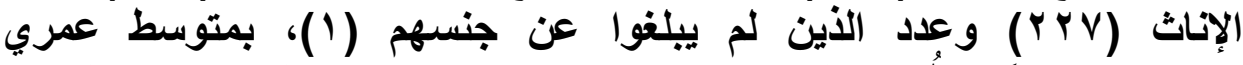

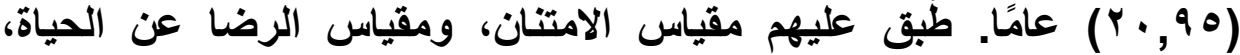

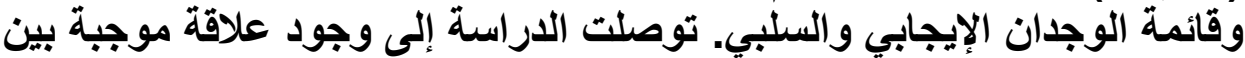

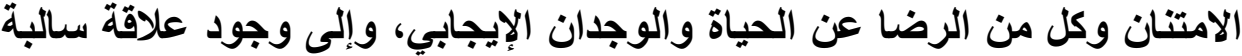

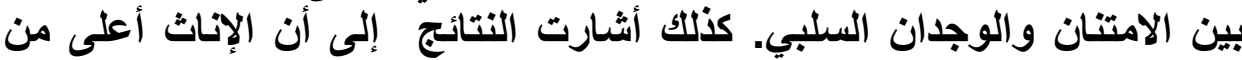

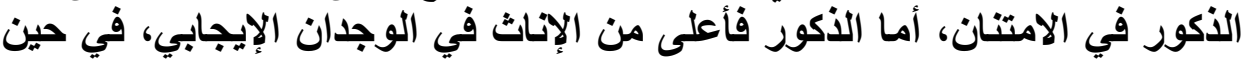

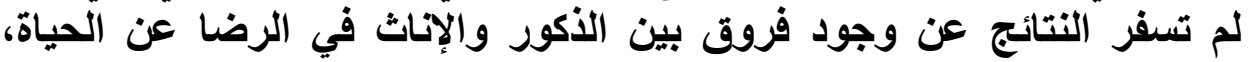
والوجدان السلبي (Sun \& Kong,2013).

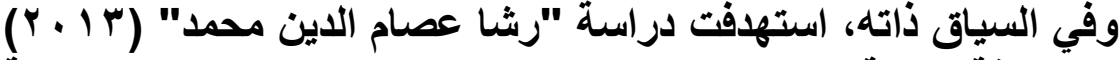

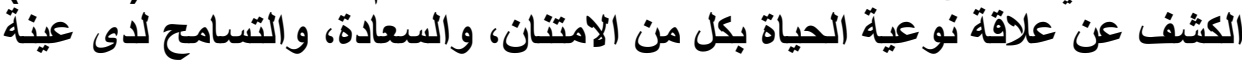

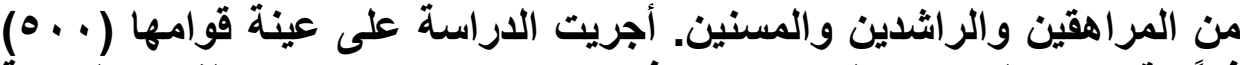

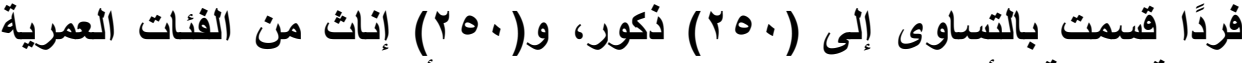

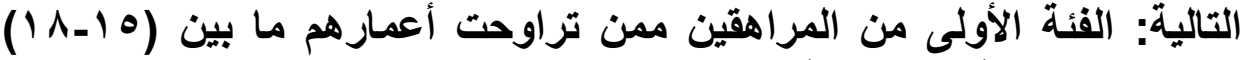

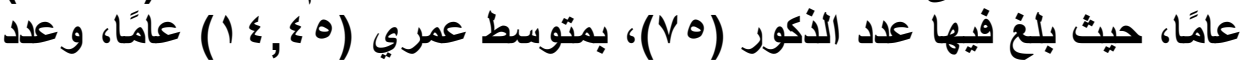

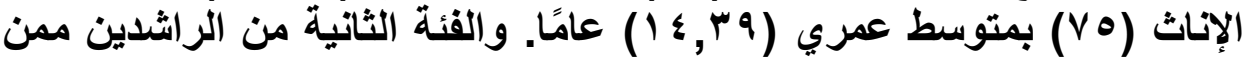

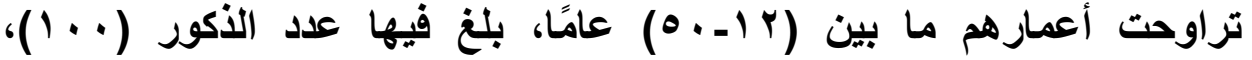

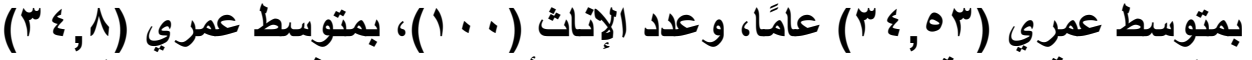

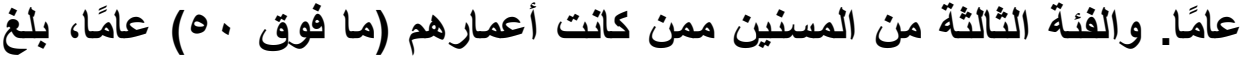

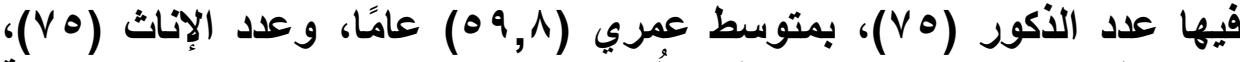

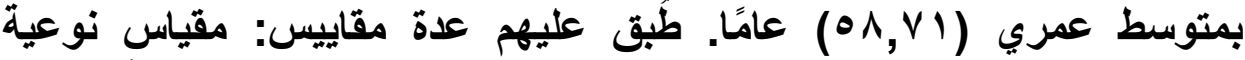

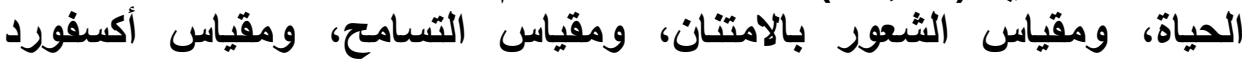

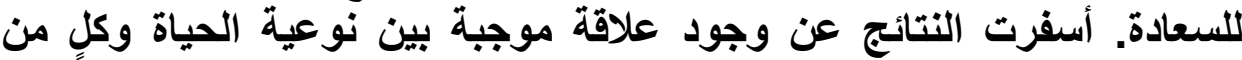

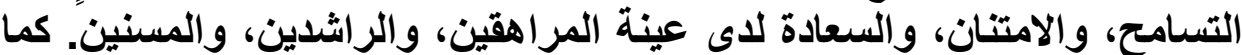

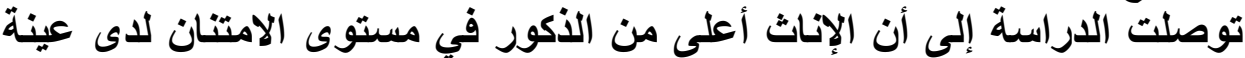

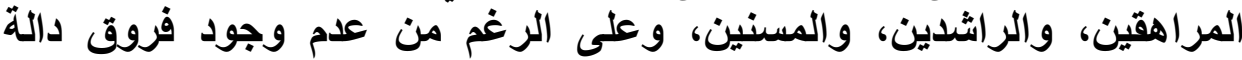

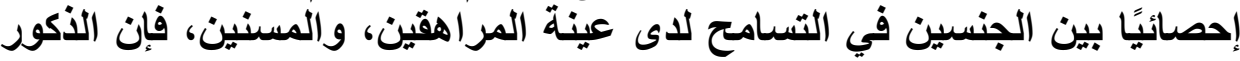

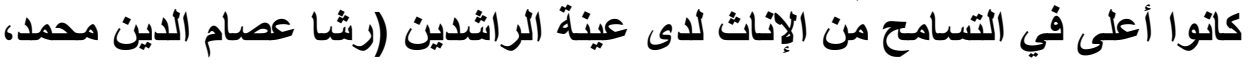
(r+1r

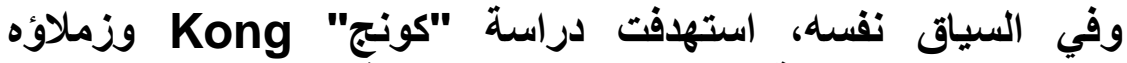
(2015) الكثف عن العلاقة بين الامتنان وتقدير الذات والداعم الاجتماعي 
والرضا عن الحياة لاى طلاب الجامعة. أجريت الدراسة على عينة من طلاب

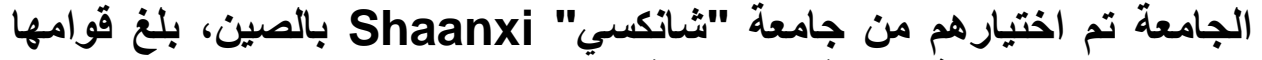

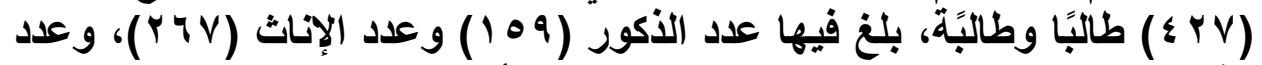

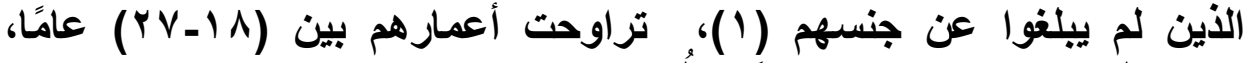

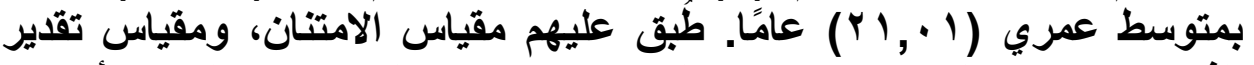

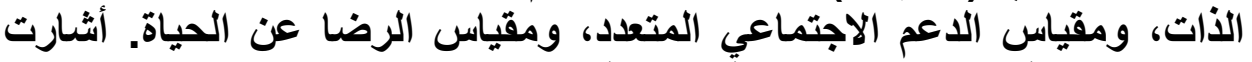

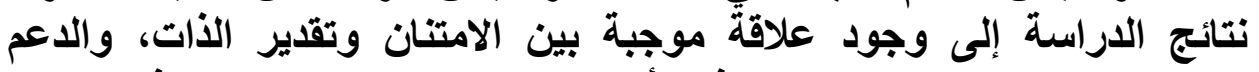

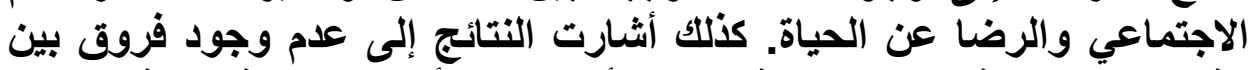

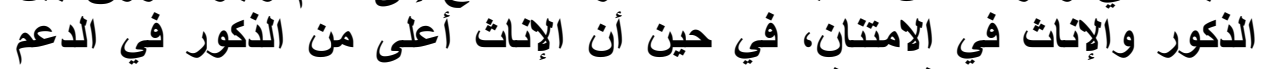

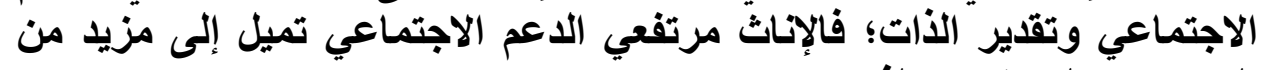

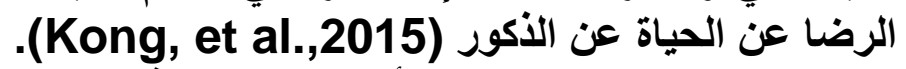

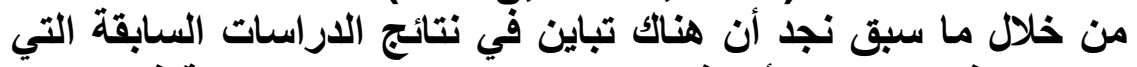

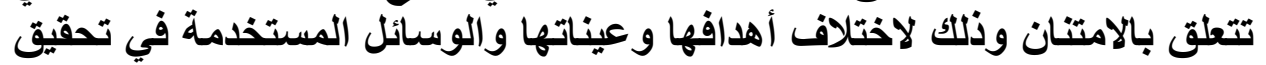

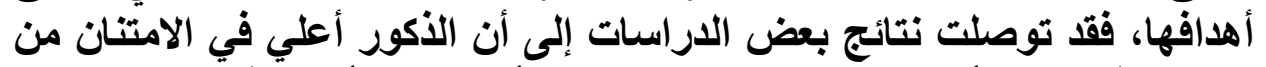

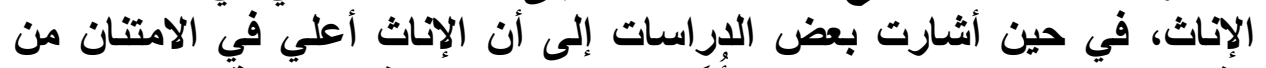

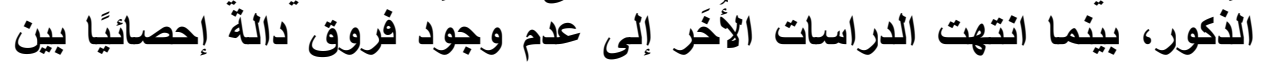

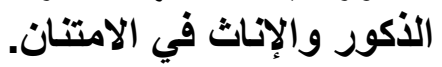

تعقبب على الدراسات السابـقة:

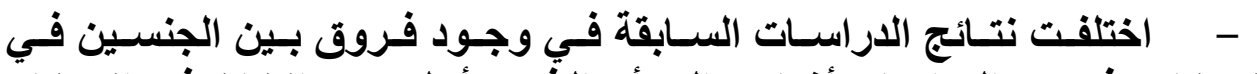

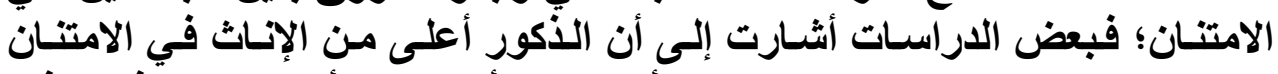

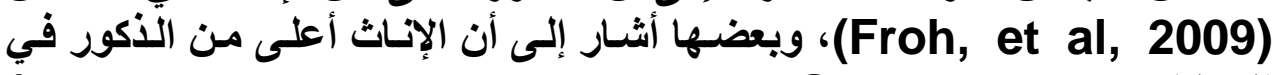
(Al-Khawaldeh \& Zegarac, 2013; Sun \& Kong, الامتنان (2013، في حين أشسار بعضـها الآخر إلى عدم وجود فروق بين الجنسين في

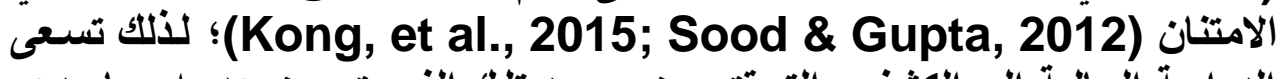

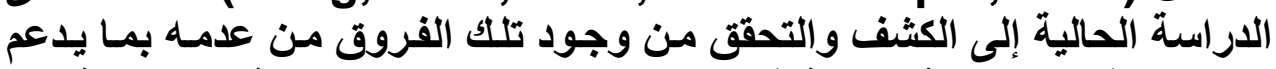

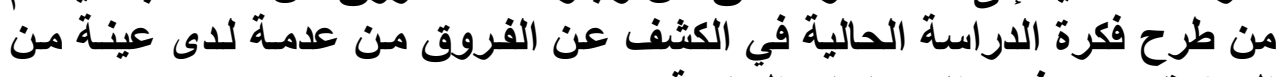
المر اهقين من ذور فرة الاحتياجات الخاصة.

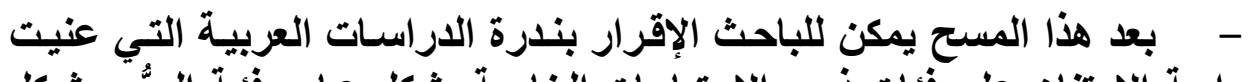

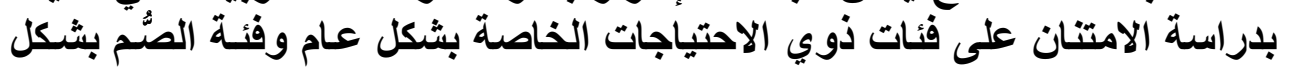
خاص.

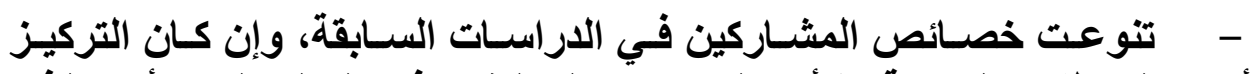

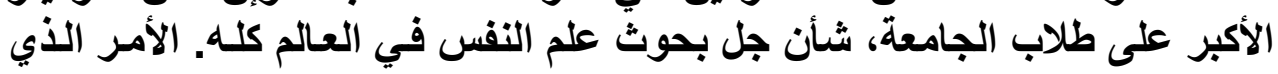




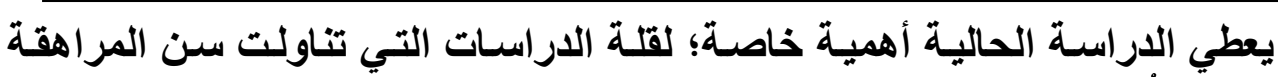
لاى ألصُّم، وذلك في حدود علم الباحثين.

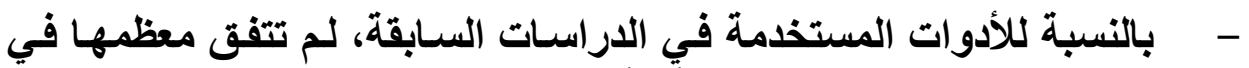

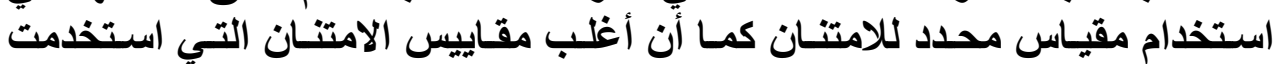

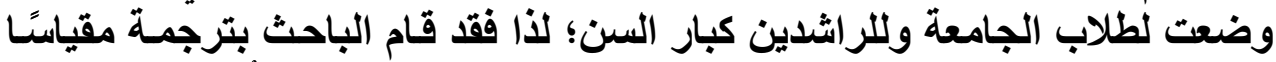

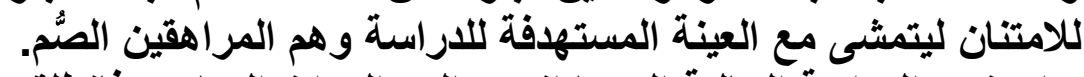

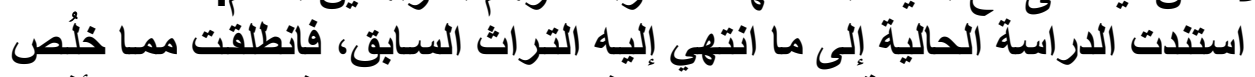

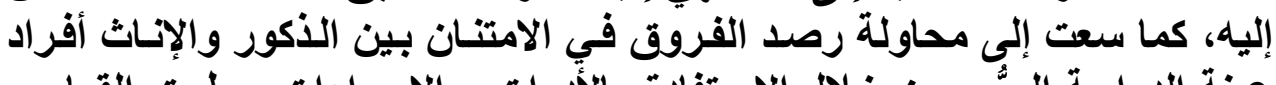

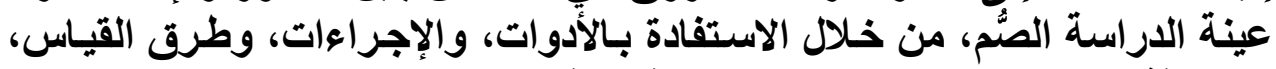

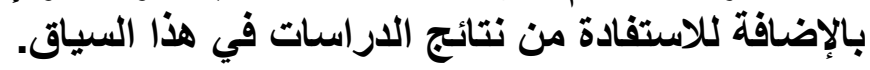

\section{فرض الدراسةة:}

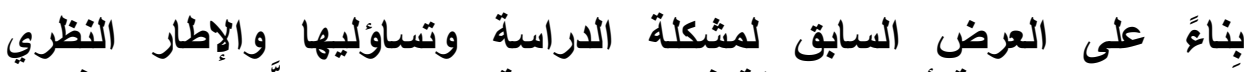

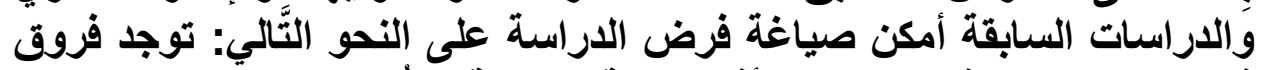

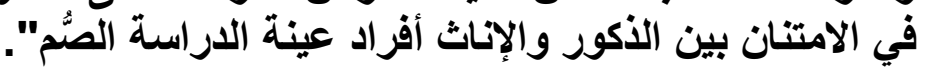

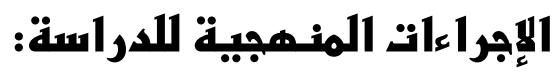

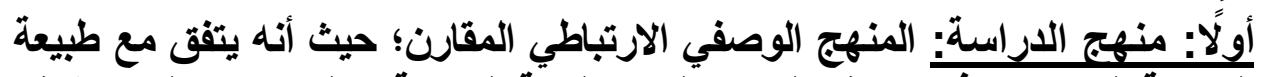

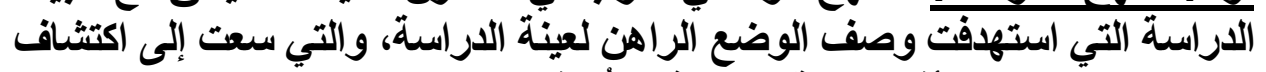
الفروق بين الجنسين أفراد عينة الاراسة الصنّم في الامتنّان.

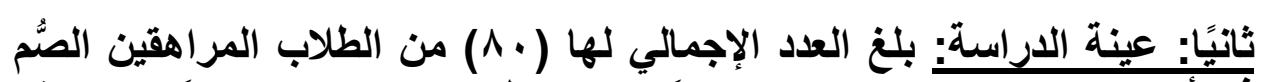

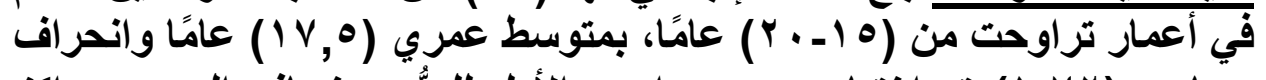

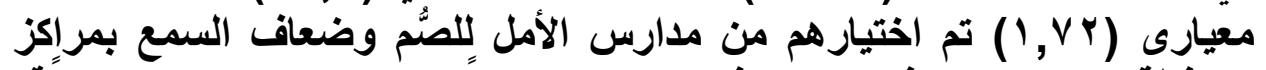

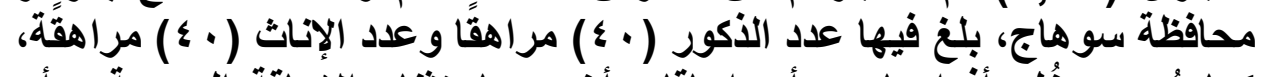

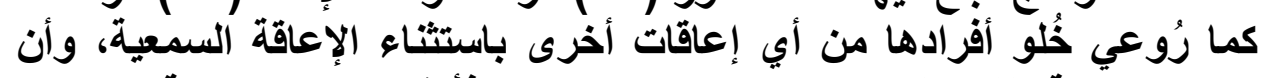

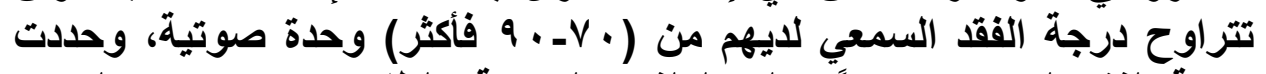

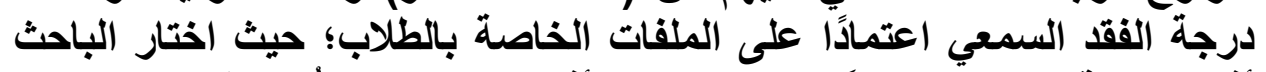

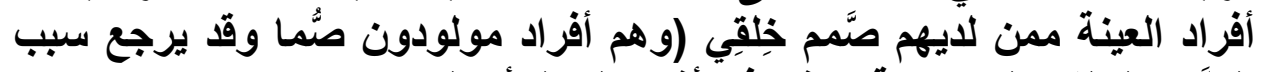

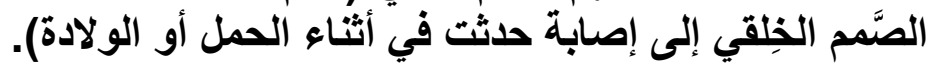




\section{ثنالثًا:أدوات الدراسةقّات:}

[1] [قياس الامتنـان:

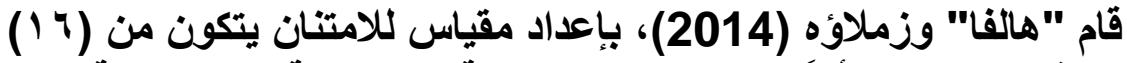

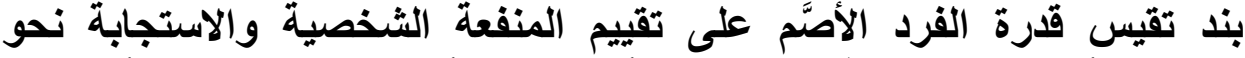

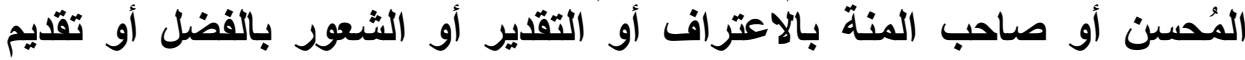

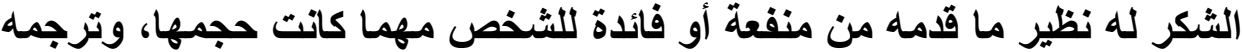

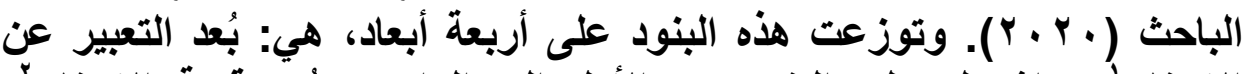

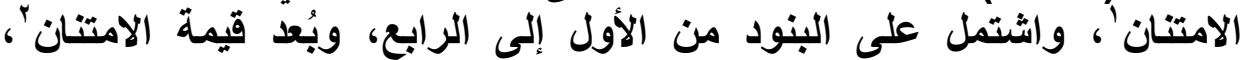

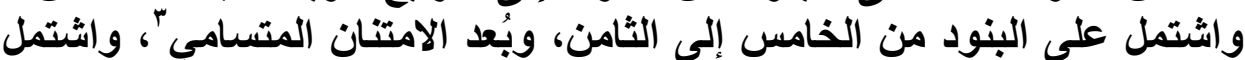

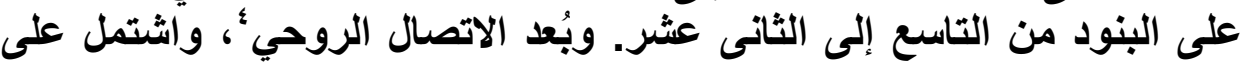

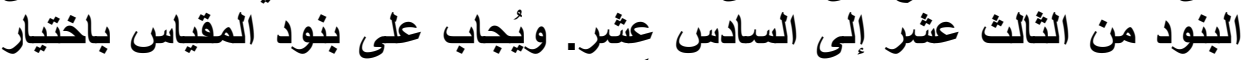

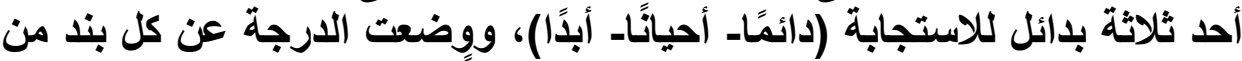

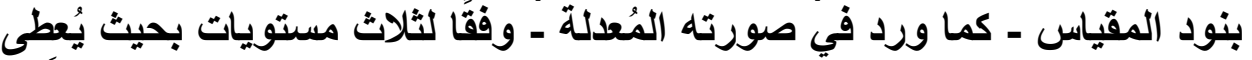

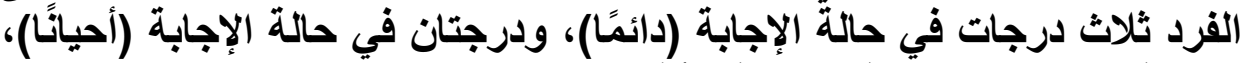

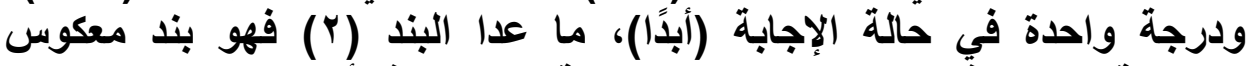

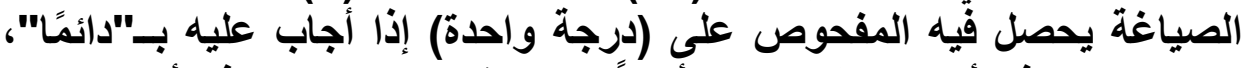

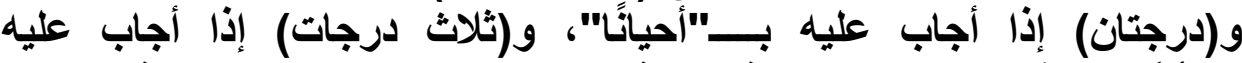

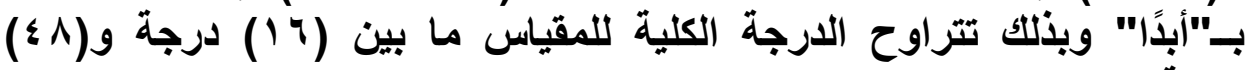
درجة.

\section{الكهاءة السيكومترية للمقياسر :}

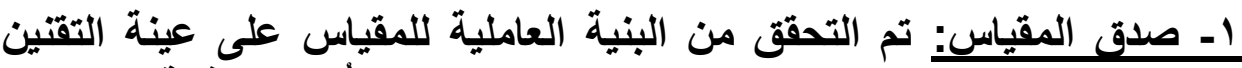

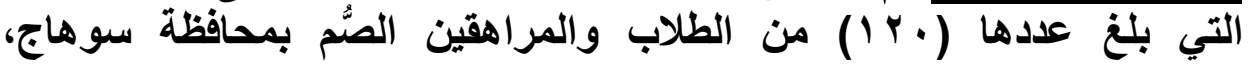

* قام الباحث بتطبيق أدوات الدراسة بلغة الإثارة بنفسه وكان التطبيق في جلسات فردية وجماعية. ${ }^{1}$ Expression of Gratitud.

${ }^{2}$ Value of Gratitude.

${ }^{3}$ Transcendent Gratitude.

${ }^{4}$ Spiritual Connection

* فـي نســـة المقيـاس الأصـلـي قامـت هالفـا" وزمـلاؤه (2005) مُعِـدو المقيـاس باسـتخراج

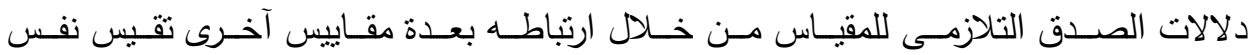

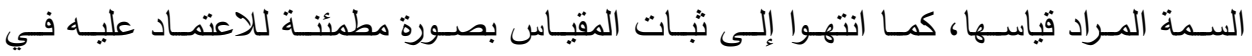


واستخدام الباحث التحليل العاملي الاستكثافي للتحقق من البنية العاملية

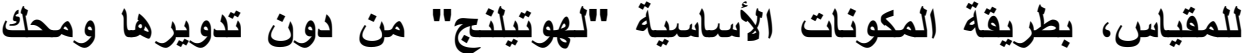

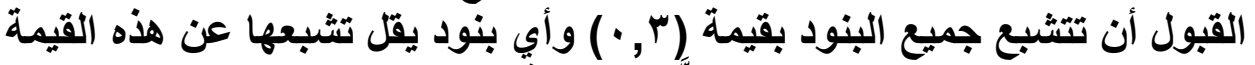

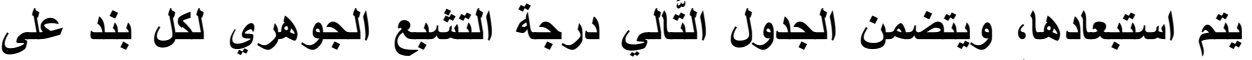
العامل المنتمية إليه وقيم الثيوع (التجانس):

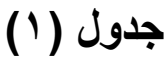

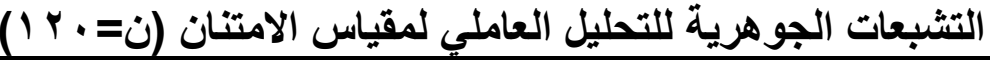

\begin{tabular}{|c|c|c|c|c|c|}
\hline قيم الشيوع & التشبع & البند & قيم الشيوع & التشبع & البند \\
\hline$\cdot, \mathrm{\vee} \wedge$ & $\cdot, \wedge r$ & 9 & $\cdot, V_{1}$ & $\cdot, 71$ & 1 \\
\hline$\cdot, \mathrm{VV}$ & $\cdot, V V$ & 1. & $\cdot, 97$ & $\cdot, \wedge 7$ & $r$ \\
\hline$\cdot, \wedge \varepsilon$ & $\cdot, \wedge V$ & 11 & $\cdot, 7 Y$ & $\cdot, \sqrt{ }$ & $r$ \\
\hline$\cdot, \wedge \wedge$ & $\cdot, \wedge \vee$ & $1 Y$ & $\cdot, \wedge 0$ & $\cdot, \wedge \mathrm{V}$ & $\varepsilon$ \\
\hline$\cdot, \wedge Y$ & $\cdot, \wedge 1$ & 14 & $\cdot, \wedge \varepsilon$ & $\cdot, \wedge 9$ & 0 \\
\hline$\cdot, \wedge \varepsilon$ & $\cdot, 9$ & $1 \varepsilon$ & $\cdot, \wedge 0$ & $\cdot, 9$. & 7 \\
\hline$\cdot, V$. & $\cdot, \wedge$. & 10 &., 79 & $\cdot, 0 \leq$ & $V$ \\
\hline$\cdot, \wedge \varepsilon$ & $\cdot, \wedge 0$ & 17 & $\cdot, 91$ & $\cdot, 9 \leq$ & $\Lambda$ \\
\hline
\end{tabular}

يتضح من خلال الجدول (1) تثبعات بنود مقياس الامتنان أعلى من المحك

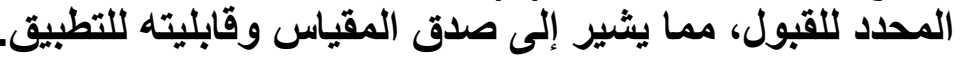

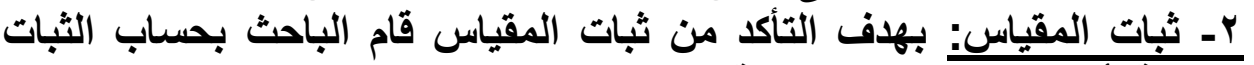

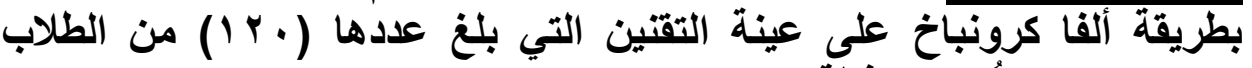

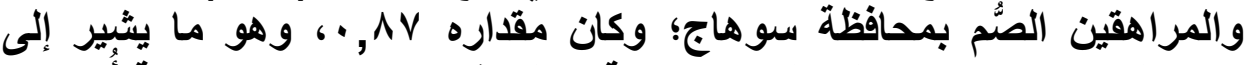

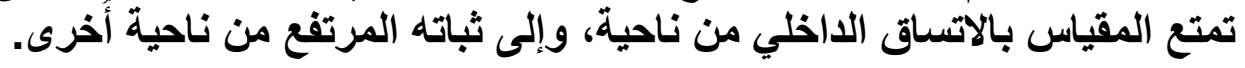

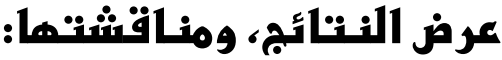

للتحقق من الفروق في الامتنان بين الأكور والإناثاث أفراد عينة الدراسة الدابة

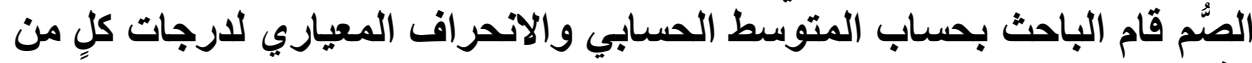

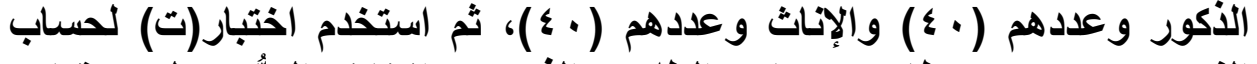

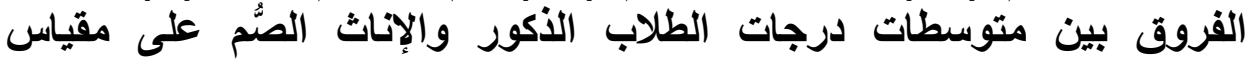

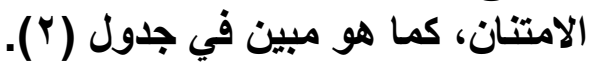




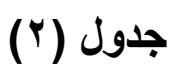

نتائج اختبار (ت) لالالة الفروق بين متوسطات درجات الطلاب الذكور والإناث الصُّم

في مقياس الامتنان (ن= • (^)

\begin{tabular}{|c|c|c|c|c|c|c|c|}
\hline \multirow{2}{*}{ الفجاه } & \multirow{2}{*}{ مستولة } & \multirow{2}{*}{ قتيمة } & \multicolumn{2}{|c|}{ إناث (ن = • • } & \multicolumn{2}{|c|}{ ذكور (ن = - ؛) } & \multirow{2}{*}{ الامتناس } \\
\hline & & & $\varepsilon$ & 5 & $\varepsilon$ & م & \\
\hline الذكور & $\cdot, \cdots 1$ & $\{, \wedge 1$ & $\cdot, \wedge$ & $৭, \wedge \mu$ & $\cdot, 90$ & $1 \cdot, \mathrm{v} \wedge$ & الالتعتير: عن \\
\hline الذكور & $\cdot, \cdots 1$ & $v, T \leqslant$ & •,Or & $9, \wedge \wedge$ & $1, \cdot \varepsilon$ & $11, \% \wedge$ & قالامتنان. \\
\hline الذكور & $\cdot, \cdots 1$ & $v, v^{4}$ & $\cdot, \vee \vee$ & $9, v_{0}$ & $1, \cdot 0$ & r $11, \mu$ & الالمتنتان \\
\hline الذكور & $\cdot, \cdots l$ & $v, 1 T$ & זיד, • & $9,9$. & $1, \cdot 9$ & & الالتصال \\
\hline الذكور & $\cdot, \cdots$ & $V, T \leqslant$ & $r, 1 \varepsilon$ & & $r, \wedge \wedge$ & $\varepsilon \varepsilon, V$. & الكلى \\
\hline
\end{tabular}

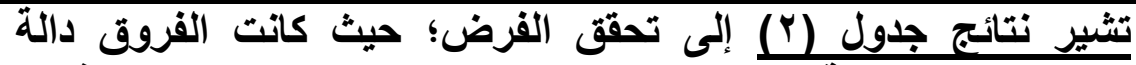

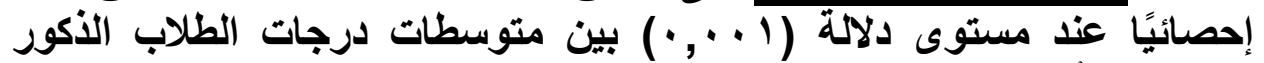
والإناث الصُّم في الدرجة الكلية لمقياس الامتتان في اتجاه الأكور.

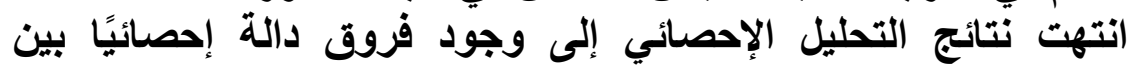

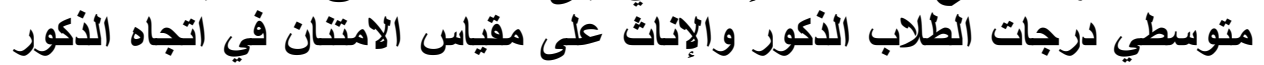

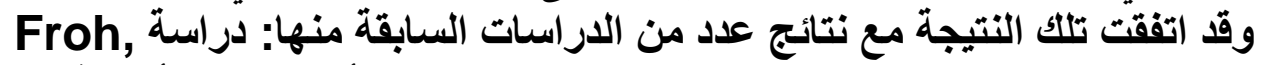
(et al.,2009; Khan \& Singh,2013)

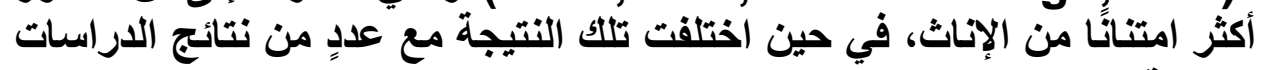

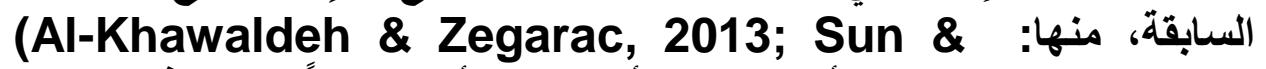
Kong, 2013 والتي أشارت إلى أن الإناث أكثر امتنانًا من الذكور، كما

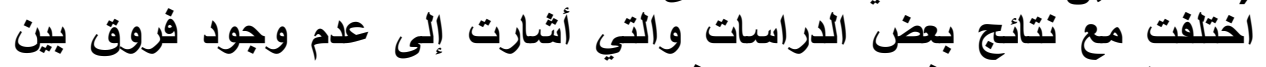
(Kong, et al., 2015; متوسطي درجات الذكور والإناث في الامتنان Sood \& Gupta, 2012)

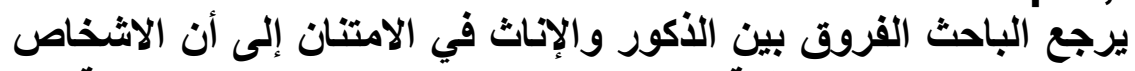

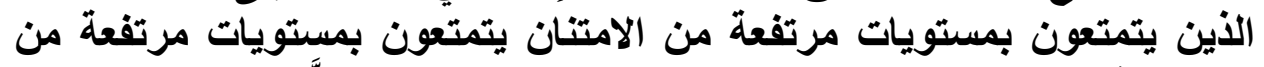

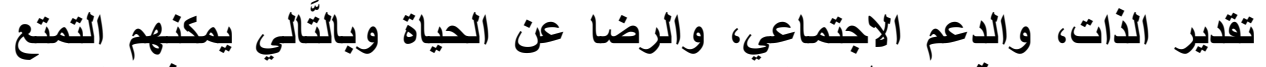

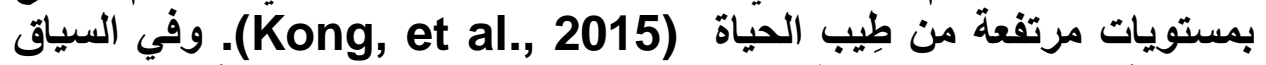
نفسه، أشارت نتائج دراسة "ماكولو" وزملاؤه (2004) إلى أن المراهقين 


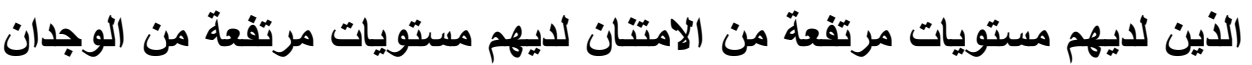

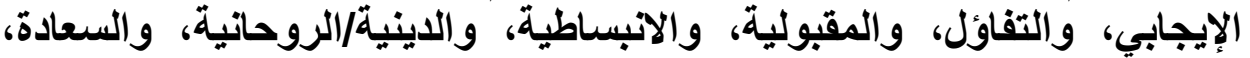

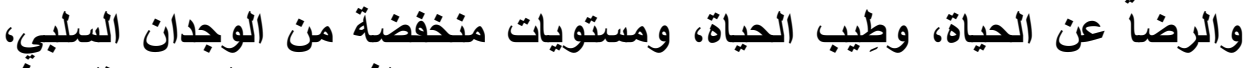

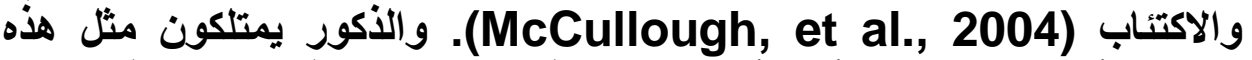

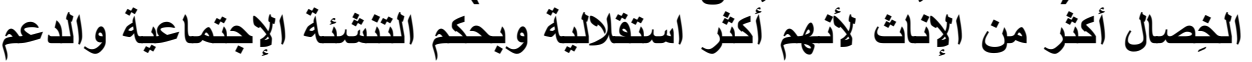

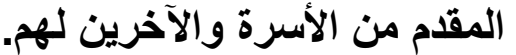

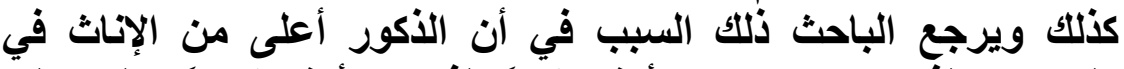

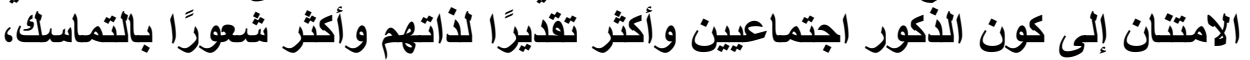

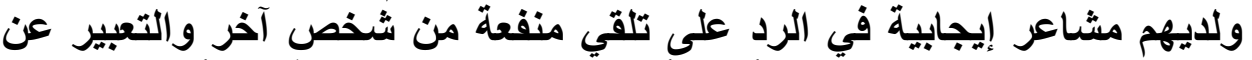

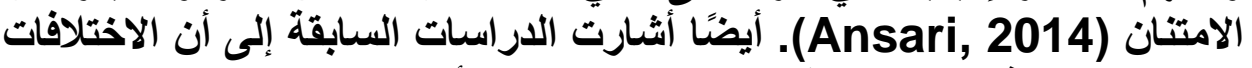

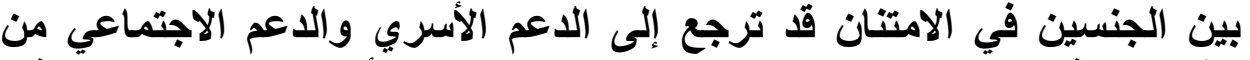

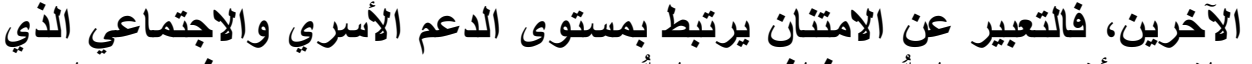

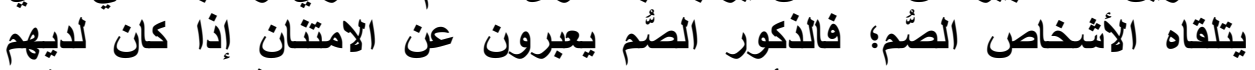

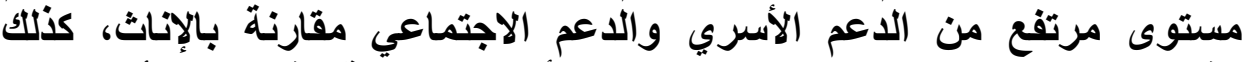

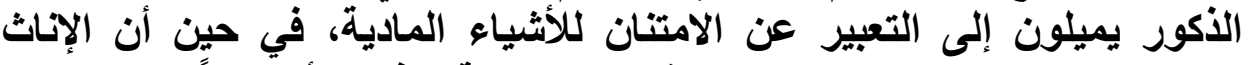

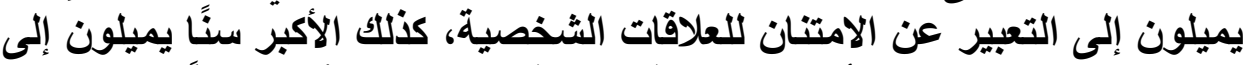

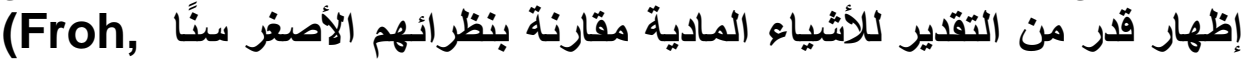
.et al.,2009) ويرجع الباحث الاختلافات بين الجنسين في الامتنان إلى الاختلافات في في

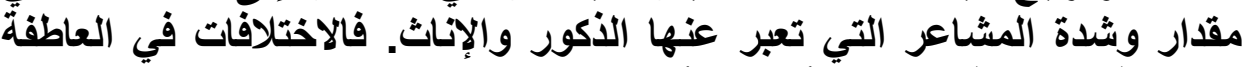

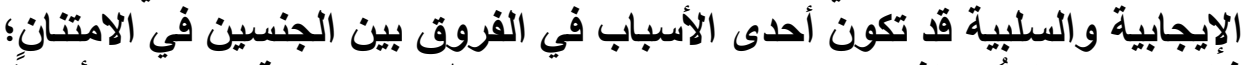

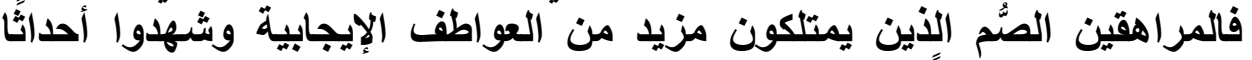

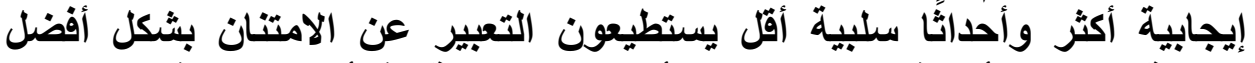

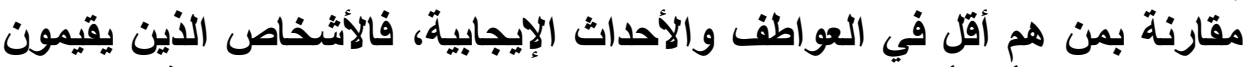

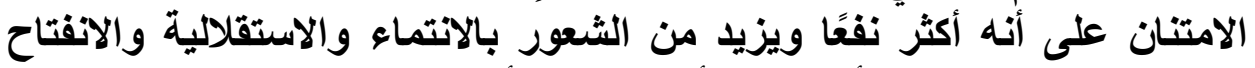

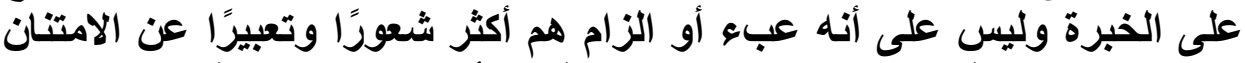

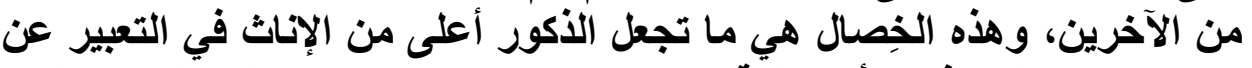

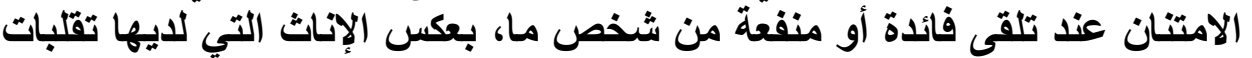
عاطفية أكثر لأنها أكثر تأثرًا بالأحداث الثخصية، وأقل في الاستقلالية والانفتاح. 


\section{مناقشة عامة لنتنائج الدراسة:}

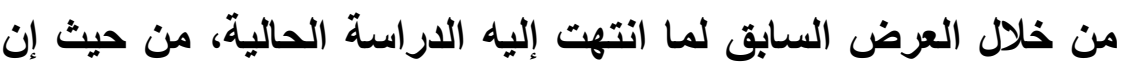

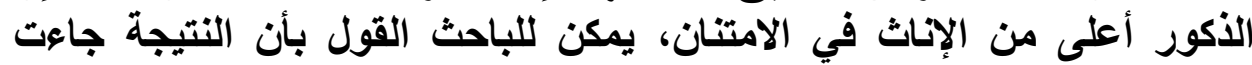

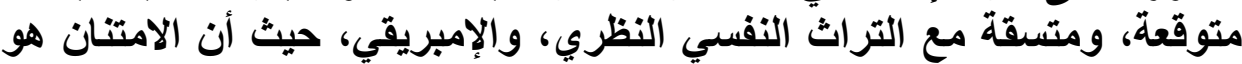

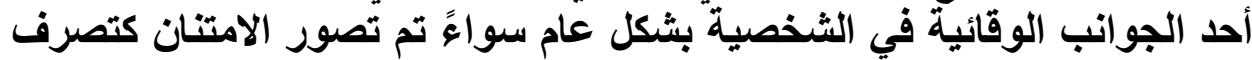

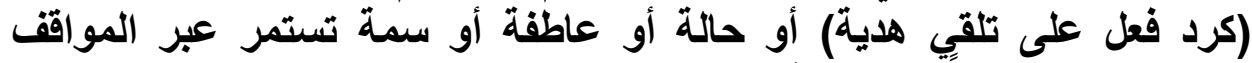

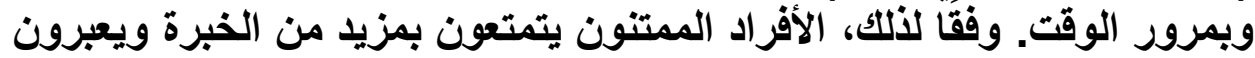

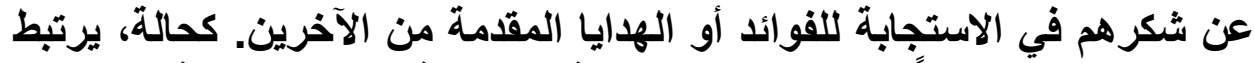

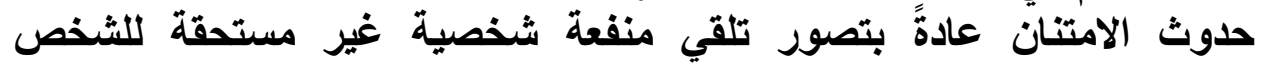

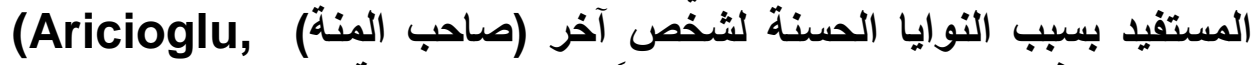

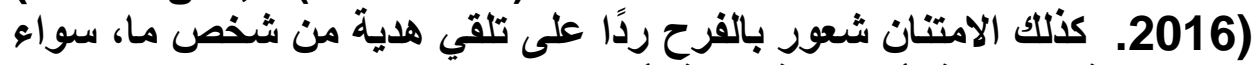

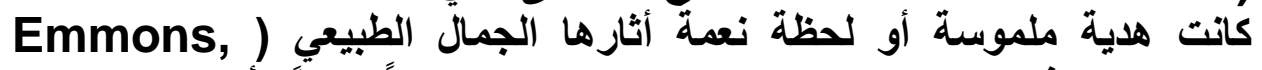

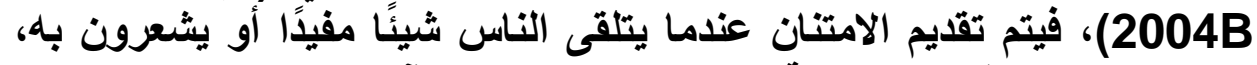

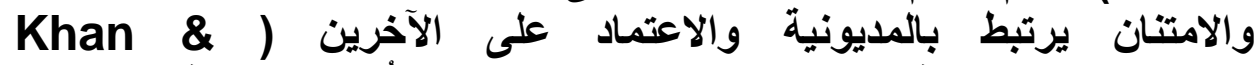
(Singh,2013). كذلك الامتنان يساعد المراهقين الصُّم على العرفان الأن بالجميل

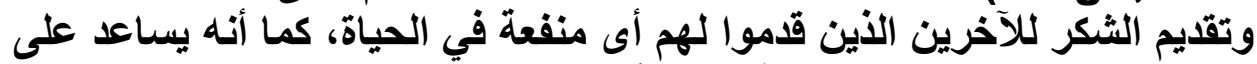

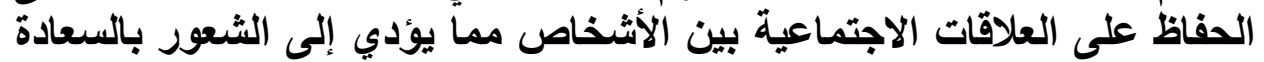
والرضا في الحياة. 


\section{قائمة الهراجه:}

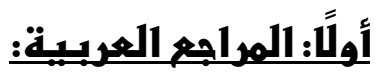

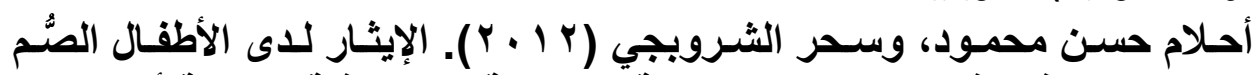
والمكفوفين في مسقط والإسكندرية: "دراسة عبر الثبر ثقافية". مجلة أمارا باك.

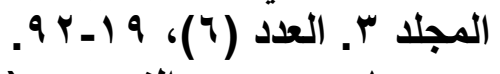

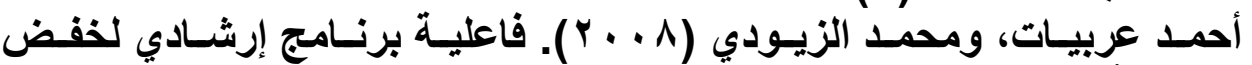

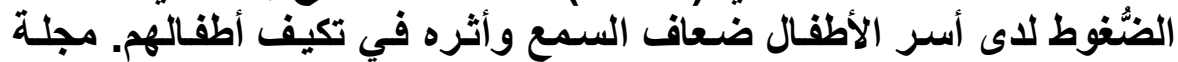

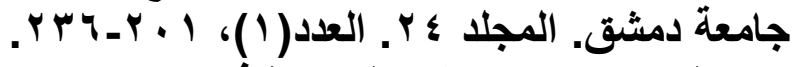

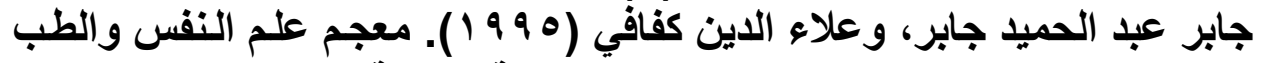

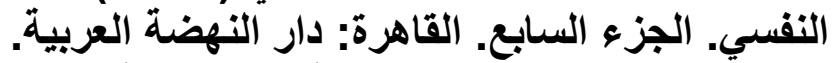

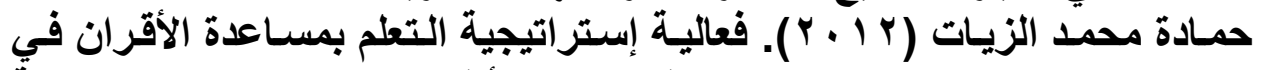

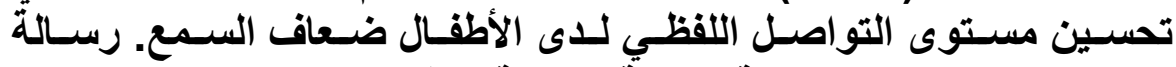

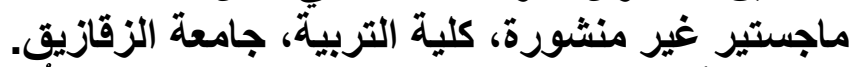

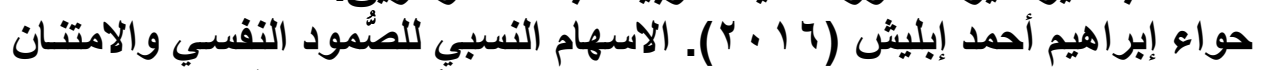

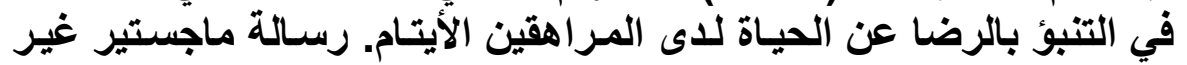

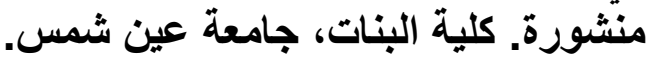

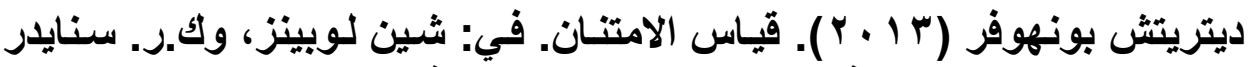

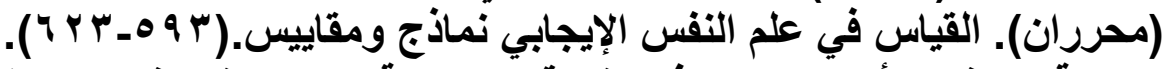

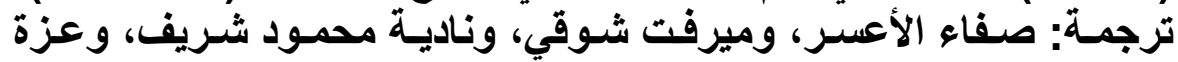

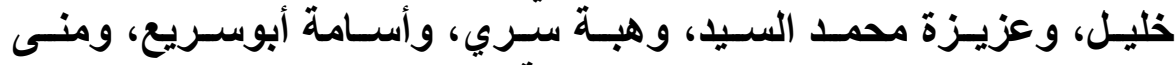

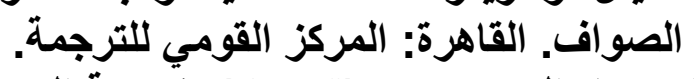

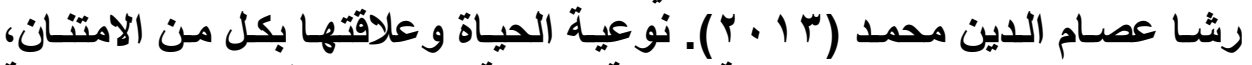

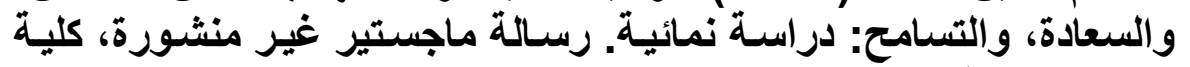

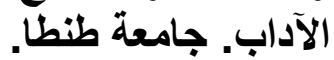

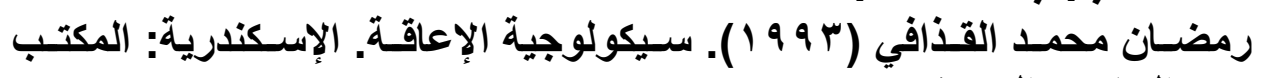

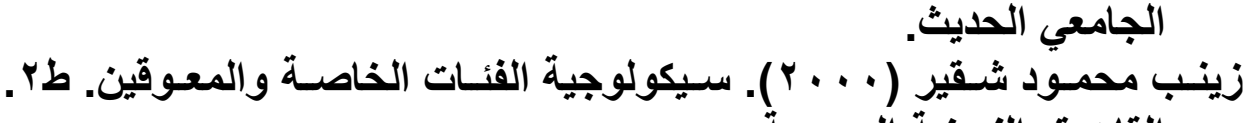
القاهرة: النهضة المصرية.

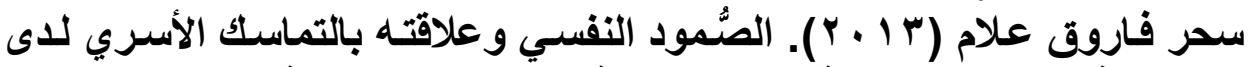

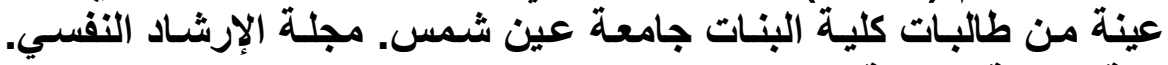

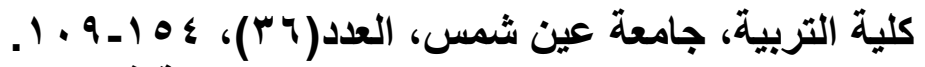

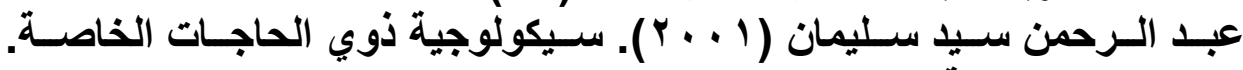
القاهرة: مكتبة زهر اءع الشرق. 


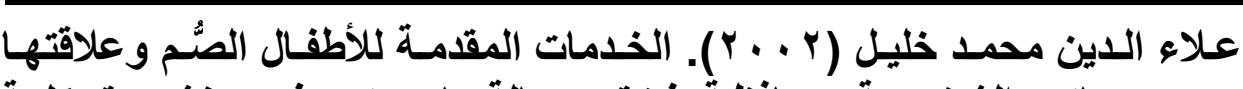

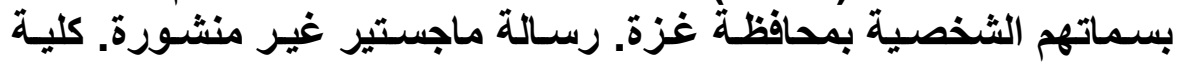

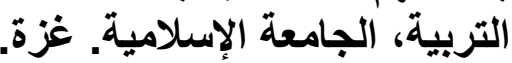

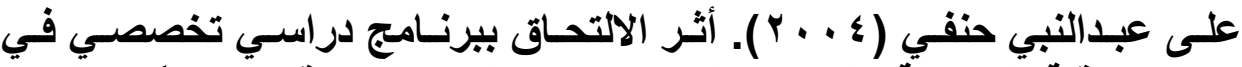

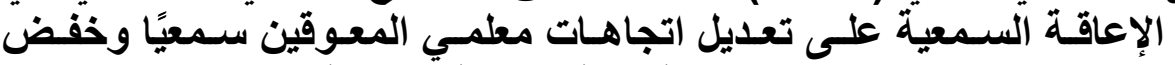

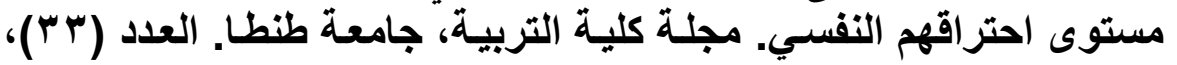
. $1-1$

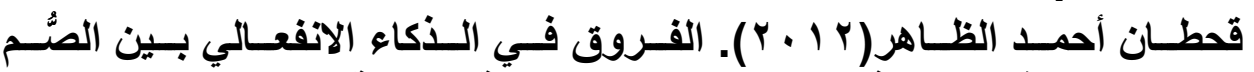

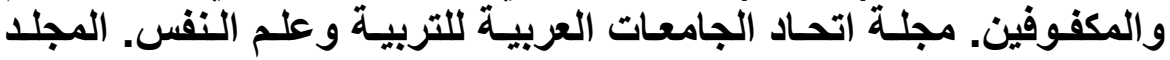

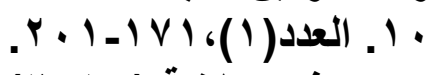

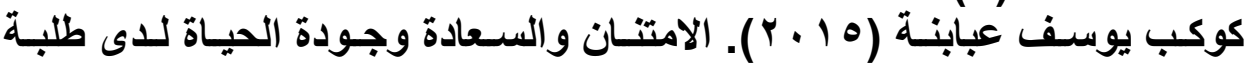

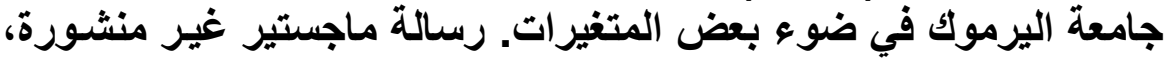
كلية التربية، جامعة اليروية فوموك.

ثانيًا: المراجير الأمنبية:

Adler, M. \& Fagley, N. (2005). Appreciation: Individual differences in finding value and meaning as a unique predictor of subjective well-being. Journal of Personality, 73(1), 79-114.

Al-Khawaldeh, N \& Zegarac,V. (2013). Gender and the Communication of Gratitude in Jordan. Open Journal of Modern Linguistics,3(3),268-287.

Ansari, S. (2014). Examining sex differences in gratitude, psychological wellbeing, and negative affectivity. Unpublished Master thesis. University of Middle Tennessee State, Murfreesboro, Tennessee.

Aricioglu, A. (2016). Mediating the Effect of Gratitude in the Relationship between Forgiveness and Life Satisfaction among University Students. International Journal of Higher Education, 5(2),275-282.

Emmons, R. \& McCullough, M. (2003). Counting blessings versus burdens: An experimental investigation of gratitude and subjective well-being in daily life. Journal of Personality and Social Psychology, 84(2), 377-389. 
Emmons, R. (2004A). Gratitude. In: Peterson, C \& Seligman, M. (Eds.), Character strengths and virtues: A hand-book and classification. (553-568). New York: Oxford University Press.

Emmons, R. (2004B). The psychology of gratitude: An introduction. In Emmons, R \& McCullough, M. (Eds.), The psychology of gratitude. (3-18). New York: Oxford University Press.

Froh, J.; Fan, J.; Emmons, R.; Bono, G.; Huebner, E. \& Watkins, P. (2011). Measuring Gratitude in Youth: Assessing the Psychometric Properties of Adult Gratitude Scales in Children and Adolescents. Psychological Assessment,23(2),311-324.

Froh, J.; Miller, D. \& Snyder, S. (2007). Gratitude in children and adolescents: Development, assessment,and school-based intervention. School Psychology Forum, 2, 1-13.

Froh, J.; Yurkewicz, C. \& Kashdan, T. (2009). Gratitude and subjective well-being in early adolescence: Examining gender differences. Journal of Adolescence, 32(3),1-18.

Hill, P. \& Allemand, M. (2011). Gratitude, forgivingness, and well-being in adulthood: Tests of moderation and incremental prediction. The Journal of Positive Psychology, 6(5),397-407.

Hlava, P.; Elfers, J. \& Offringa, R. (2014). A transcendent view of gratitude: The transpersonal gratitude scale. International Journal of Transpersonal Studies, 33(1), 114.

Khan, I. \& Singh, N. (2013). A Study on Gender Differences on Gratitude, Spirituality and Forgiveness Among School Teachers. International Journal of Applied Sciences \& Engineering (IJASE), 1(1), 9-14.

Kong, F.; Ding, K. \& Zhao, J. (2015). The Relationships Among Gratitude, Self-esteem, Social Support and Life 
Satisfaction Among Undergraduate Students. Journal of Happiness Studies, 16(2),477-489.

Lambert, N.; Fincham, F.; Stillman, T. \& Dean, L. (2009). More gratitude, less materialism: The mediating role of life satisfaction. The Journal of Positive Psychology, 4(1),32-42.

Marschark, M. (2007). Raising and educating a deaf child: a comprehensive guide to choices, controversies, and decisions faced by parents and educators. 2nd ed. New York: Oxford University Press, Inc.

McCullough, M.; Emmons, R \& Tsang, J. (2002). The grateful

disposition: A conceptual and empirical topography. Journal

Personality and Social Psychology, 82(1), 112-127.

Mccullough, M.; Tsang, J. \& Emmons, R. (2004). Gratitude in intermediate affective terrain. Links of Grateful moods with individual differences and daily emotional experience. Journal of Personality and Social Psychology, 86(2), 295-309.

Morehead, P. (2001). New American Roget's College Thesaurus in Dictionary Form. $4^{\text {th }}$ ed. London: Penguin. Polak, E \& McCullough, M. (2006). Is Gratitude an alternative to materilism?. Journal of Happiness Studies, 7,343-360.

Robustelli, B \& Whisman, M. (2016). Gratitude and Life Satisfaction in the United States and Japan. Journal of Happiness Studies, 1-15.

Sheridan, M. (2011). Whose literacy is it, Anyway? trengths-Based guidelines for transforming the developmental environments of deaf children and adolescents. In: Zand, D. and Pierce, K. (Eds.). Resilience in Deaf Children: Adaptation Through Emerging Adulthood. (229-249). NY: Library of Congress. 
Sood, S. \& Gupta, R. (2012). A study of gratitude and well being among adolescen. IOSR Journal Of Humanities And Social Science (IOSR-JHSS),3(5)35-38.

Sun, J. \& Stewart, D. (2007). Age and gender effects on resilience in children and adolescents. The International Journal of Mental Health Promotion, 9(4), 16-25.

Sun, P \& Kong, F. (2013). Affective Mediators of the Influence of Gratitude on Life Satisfaction in Late Adolescence. Social Indicators Research,114(3),13611369.

Tsang, J. (2006). Gratitude and prosocial behaviour: An experimental test of gratitude. Cognition \& Emotion, 20(1), 138-148.

VandenBos, G. (2015). Dictionary of Psychology. Washington, D. C.: American Psychological Association.

Watkins, P.; Woodward, K.; Stone, T., \& Kolts, R. (2003). Gratitude and happiness: Development of a measure of gratitude, and relationships with subjective well-being. Social Behavior and Personality: An International Journal,31(5),431-452.

Wood, A.; Froh, J. \& Geraghty, A. (2010). Gratitude and well-being: A review and theoretical integration. Clinical Psychology Review, 30(7),890-905.

Wood, A.; Maltby, J.; Stewart, N., \& Joseph, S. (2008). Conceptualizing gratitude and appreciation as a unitary personality trait. Personality and Individual Differences, 44(3),619-630. 


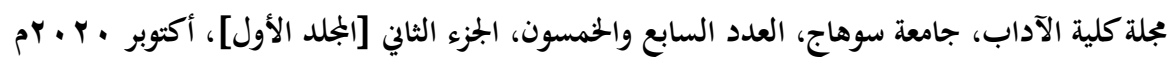

Gender Differences in Gratitude among Deaf Adolescents Mohamed Abd-Elazeem khalaf-Allah Instructor, Psychology Department, Faculty of Arts, Sohag University

E-mail: mohamedabdo_20th@yahoo.com

Abstract

The present study aimed to identify the gender differences in gratitude in a sample of (80) deaf adolescents with a mean age of (17.50) years \pm (1.72). The gratitude scale developed by Halfa et al. (2014) and translated by the researcher was applied. The study showed statistically significant differences between males and females in gratitude in favor of the males. The findings were discussed in the light of psychological literature.

Keywords: Gratitude, Gender, Adolescents, Deaf. 
